\title{
Psychosocial treatments for negative symptoms in schizophrenia: Current practices and future directions
}

\author{
Ori Elis ${ }^{1}$, Janelle M. Caponigro ${ }^{*, 1}$, Ann M. Kring \\ Department of Psychology, University of California, Berkeley, USA
}

\section{H I G H L I G H T S}

- We review studies that report on negative symptom outcomes in schizophrenia.

- At best, psychosocial treatments show moderate improvements in negative symptoms.

- Cognitive behavior therapy and social skills training show the most promise.

- We identify future directions for the development of negative symptom interventions.

\section{A R T I C L E I N F O}

\section{Article history:}

Received 13 September 2012

Revised 31 May 2013

Accepted 8 July 2013

Available online 16 July 2013

\section{Keywords:}

Schizophrenia

Negative symptoms

Treatment

Psychosocial interventions

\begin{abstract}
A B S T R A C T
Schizophrenia can be a chronic and debilitating psychiatric disorder. Though advancements have been made in the psychosocial treatment of some symptoms of schizophrenia, people with schizophrenia often continue to experience some level of symptoms, particularly negative symptoms, throughout their lives. Because negative symptoms are associated with poor functioning and quality of life, the treatment of negative symptoms is a high priority for intervention development. However, current psychosocial treatments primarily focus on the reduction of positive symptoms with comparatively few studies investigating the efficacy of psychosocial treatments for negative symptoms. In this article, we review and evaluate the existing literature on three categories of psychosocial treatments - cognitive behavioral therapy (CBT), social skills training (SST), and combined treatment interventions - and their impact on the negative symptoms of schizophrenia. Of the interventions reviewed, CBT and SST appear to have the most empirical support, with some evidence suggesting that $\mathrm{CBT}$ is associated with maintenance of negative symptom improvement beyond six months after treatment. It remains unclear if a combined treatment approach provides improvements above and beyond those associated with each individual treatment modality. Although psychosocial treatments show promise for the treatment of negative symptoms, there are many unanswered questions about how best to intervene. We conclude with a general discussion of these unanswered questions, future directions and methodological considerations, and suggestions for the further development of negative symptom interventions.
\end{abstract}

(c) 2013 Elsevier Ltd. All rights reserved.

\section{Contents}

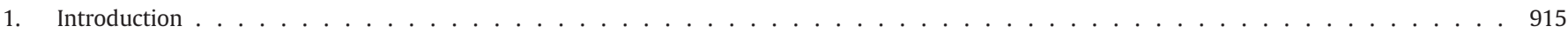

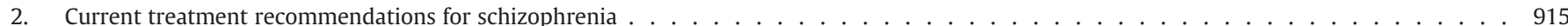

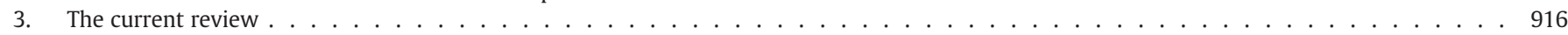

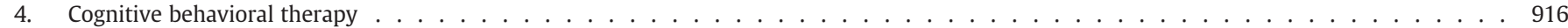

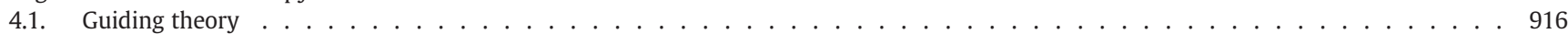

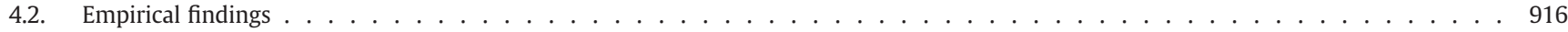

4.2.1. CBT compared to non-active treatments . . . . . . . . . . . . . . . . . . . . . . . . . . . . .

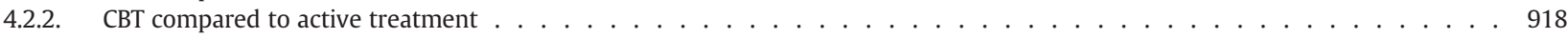

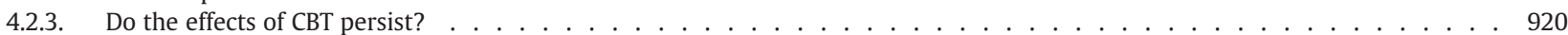

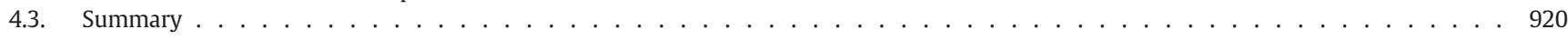

\footnotetext{
* Corresponding author at: Department of Psychology, University of California, Berkeley, 3210 Tolman Hall \#1650, CA 94720, USA. Tel.: +1 510 643 4098 ; fax: + 1510 642 5293. E-mail address: jmcaponigro@berkeley.edu (J.M. Caponigro).

1 Ori Elis and Janelle M. Caponigro contributed equally to this review and share first authorship.
} 
5. Social skills training . . . . . . . . . . . . . . . . . . . . . . . . . . . . . . . . . . . . . . . . . . 921

5.1. Guiding theory . . . . . . . . . . . . . . . . . . . . . . . . . . . . . . . . . . . . . . 921

5.2. Empirical findings . . . . . . . . . . . . . . . . . . . . . . . . . . . . . . . . . . . . . . . . . . . 921

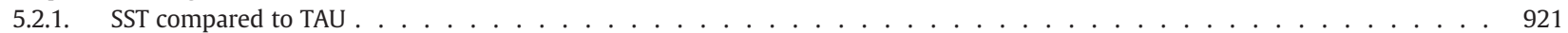

5.2.2. SST compared to an active control treatment . . . . . . . . . . . . . . . . . . . . . . . . . . . . . 921

5.3. Summary . . . . . . . . . . . . . . . . . . . . . . . . . . . . . . . . . . 921

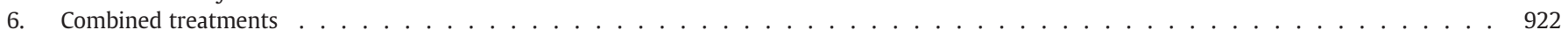

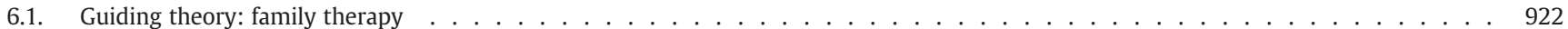

6.2. Guiding theory: psychoeducation . . . . . . . . . . . . . . . . . . . . . . . . . . . . . . . . . . 922

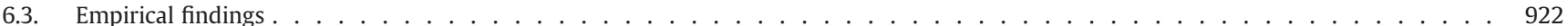

6.3.1. Combined treatments with family therapy . . . . . . . . . . . . . . . . . . . . . . . . . . . . . . . . 922

6.3.2. Combined treatments with psychoeducation . . . . . . . . . . . . . . . . . . . . . . . . . . . . . . 923

6.3.3. Combined treatments with SST or CBT . . . . . . . . . . . . . . . . . . . . . . . . . . . . . . . . . . . 923

6.4. Summary. . . . . . . . . . . . . . . . . . . . . . . . . . . . . . . . . . . . . . . . 924

7. General discussion . . . . . . . . . . . . . . . . . . . . . . . . . . . . . . . . . . . . . . . . . . 924

8. Future directions . . . . . . . . . . . . . . . . . . . . . . . . . . . . . . . . . . . . . . . . . . . 925

8.1. New wave of treatments . . . . . . . . . . . . . . . . . . . . . . . . . . . . . . . . . . . . . 925

8.2. Standardization of study measurement and design . . . . . . . . . . . . . . . . . . . . . . . . . . . . . . . . . . . . 925

8.3. Additional considerations in treatment development . . . . . . . . . . . . . . . . . . . . . . . . . . . . . 926

References . . . . . . . . . . . . . . . . . . . . . . . . . . . . . . . . . . . . . . 926

\section{Introduction}

Schizophrenia can be a debilitating disorder that affects the way a person thinks, feels, and behaves. The DSM-5 (American Psychiatric Association, 2010) diagnostic criteria for schizophrenia include delusions (e.g., beliefs not rooted in reality), hallucinations (e.g., sensory experiences not rooted in reality), disorganized speech (e.g., incoherent verbal communication), disorganized behavior or catatonia (e.g., inappropriate or unusual actions or movements), and negative symptoms (e.g., diminished motivation or behavior). At least one of the two symptoms must include delusions, hallucinations, or disorganization, and the symptoms must cause functional impairment and persist for six months either in their "active phase" or in a more residual manner.

Consensus in the field suggests that there are five negative symptoms: blunted affect, alogia, asociality, anhedonia, and avolition (Kirkpatrick, Fenton, Carpenter, \& Marder, 2006). These symptoms are referred to as 'negative' because they involve an absence of or deficits in experiences that are typically present in healthy people. Blunted affect, or affective flattening, refers to decreased or restricted emotional expression, including the range and intensity of facial, vocal, and nonverbal expression. Alogia, or poverty of speech, is decreased verbal production or fluency. Asociality involves decreased interest, motivation, or desire to spend time with others; it is most easily identified behaviorally as a lack of meaningful relationships with friends or families. Anhedonia is a decreased ability to experience pleasure from activities that are usually found enjoyable. Recent research points to an important distinction between in-the-moment, or consummatory, pleasure (e.g., enjoying a tasty slice of pizza) and anticipatory pleasure (e.g., anticipating a delicious slice of pizza for lunch). In schizophrenia, it appears that while consummatory pleasure remains intact, anticipating future pleasurable experiences is problematic (Gard, Kring, Germans Gard, Horan, \& Green, 2007; Kring \& Caponigro, 2010). Finally, avolition is a deficit in the ability to initiate and persist in goal-directed behavior. This symptom involves both the desire to pursue tasks and the ability to follow through to completion.

Factor analytic studies have indicated that the five negative symptoms can be more parsimoniously explained by two factors: 1) diminished expression, including the symptoms of blunted affect and alogia; and 2) diminished motivation and pleasure, including the symptoms of avolition, anhedonia and asociality (Blanchard \& Cohen, 2006; Horan, Kring, Gur, Reise, \& Blanchard, 2011; Kring, Gur, Blanchard, Horan, \& Reise, 2013). The DSM-5 description of negative symptoms parallels this conceptualization, defining negative symptoms as being composed of restricted affect and restricted avolition/asociality.
Approximately 15-20\% of people with schizophrenia experience negative symptoms that persist during periods of clinical stability and remain untouched by current treatments (Buchanan, 2007). Furthermore, negative symptoms are associated with poor functional outcomes (e.g., Herbener \& Harrow, 2004; Milev, Ho, Arndt, \& Andreasen, 2005). Thus, interventions that are designed to treat negative symptoms are of high priority since negative symptoms are strongly related to functional outcomes and they have an independent effect on outcomes relative to other schizophrenia symptoms (Rabinowitz et al., 2012).

\section{Current treatment recommendations for schizophrenia}

Though advancements have been made in the treatment of schizophrenia over the last decades, reducing the "revolving door" of stabilization and re-hospitalization, people with schizophrenia often experience residual symptoms, significantly affecting their quality of life. Medications are used as the first line of treatment to help reduce acute symptom exacerbation and as a maintenance treatment in order to reduce the risk of relapse (Buchanan et al., 2010). Unfortunately, pharmacological treatments have limited effects on negative symptoms and may even contribute to or exacerbate secondary negative symptoms (Buchanan et al., 2010; for a metaanalysis, see Leucht et al., 2009).

Psychosocial interventions, as an adjunct treatment to medications, are now a widely accepted treatment approach to help target areas of impairment, providing additional relief from the distress of symptoms. In fact, current treatment recommendations for schizophrenia from the Patient Outcomes Research Team (PORT) specify medications plus psychosocial interventions (Dixon et al., 2010). Current psychosocial treatments for schizophrenia, however, have been mostly one-sided, with treatments primarily targeting positive symptoms (i.e., delusions or hallucinations). This is surprising given that the negative symptom domains of diminished expression and motivation/pleasure have been considered a central component of the illness dating back to when it was first described (Bleuler, 1950; Kraepelin, 1919). The only psychosocial intervention included in the PORT recommendations for the treatment of negative symptoms is cognitive behavioral therapy (CBT) and as we review later, $C B T$ intervention studies have yielded mixed findings, with some showing improvements in negative symptoms and others showing no change (Wykes, Steel, Everitt, \& Tarrier, 2008). Although other interventions have shown promise for improving negative symptoms, their efficacy is modest at best (Erhart, Marder, \& Carpenter, 2006). Thus, the American Psychiatric Association's guide for clinical treatment has reported, "There are no 
treatments with proven efficacy for primary negative symptoms" (APA, 2004), pointing to an unmet therapeutic need and opening the door for future intervention development.

\section{The current review}

Although there have been prior reviews focused on specific psychosocial treatments in schizophrenia (e.g., Gould, Mueser, Bolton, Mays, \& Goff, 2001; Turkington, Dudley, Warman, \& Beck, 2006), the current review systematically and critically evaluates studies that have assessed the impact of psychosocial interventions on negative symptoms. Articles were identified via several databases (PubMed, PsycInfo, and Google Scholar) using both broad (e.g. therapy [OR] psychosocial [OR] treatment [AND] schizophrenia) and narrow (e.g. cognitive [OR] behavioral [OR] psychoeducation [OR] social skills [AND] schizophrenia) search terms (keywords and anywhere in the manuscript). Search results were pared down to only include randomized control trials and exclude medication efficacy studies, theoretical papers, case studies, studies of high-risk populations, meta-analyses, and reviews. Meta-analyses and reviews were, however, used in order to identify additional studies that were not initially identified in the database searches.

Of the studies identified, only a small number $(n=8)$ included negative symptoms as a primary treatment outcome (Daniels, 1998; Dobson, McDougall, Busheikin, \& Aldous, 1995; Dyck et al., 2000; Grant, Huh, Perivoliotis, Stolar, \& Beck, 2012; Hayes, Halford, \& Varghese, 1995; Klingberg et al., 2009, 2011; Thorup et al., 2005; Turkington, Dudley, et al., 2006; Turkington, Kingdon, et al., 2006), and only one study (Klingberg et al., 2009, 2011) tested an intervention explicitly designed to alleviate negative symptoms. Instead, the studies reported here evaluated psychosocial interventions for schizophrenia more broadly, and findings regarding negative symptoms were often only briefly mentioned. In the current review, we opted to include psychosocial interventions with at least ten or more randomized controlled trials (RCT), reasoning that this would be a sufficient sample from which to make comparisons across studies and conclusions regarding the efficacy of a particular intervention for improving negative symptoms. Cognitive behavioral therapy (CBT), social skills training (SST), and combined treatment interventions (i.e., more than one psychosocial intervention delivered together) met this criterion of ten or more RCTs that also reported on negative symptom outcomes. For each treatment, we discuss the guiding theory as well as the empirical support for improving negative symptoms. Furthermore, we highlight strengths and weaknesses of individual studies and of the larger body of findings specific to each treatment approach and consider aspects of study design. Tables 1-3 list information on all of the studies reviewed here, including sample and size, nature of treatment and control interventions, some study design details such as whether raters were blinded to treatment condition, and effect sizes when they are reported. Finally, in delineating future directions, we discuss recent innovations in the treatment of negative symptoms and provide several important methodological considerations that ought to be included in the next generation of efficacy and effectiveness studies.

\section{Cognitive behavioral therapy}

\subsection{Guiding theory}

Cognitive behavioral therapy (CBT) is a widely established and effective transdiagnostic treatment (Beck, 2011). The cognitive model suggests that the way in which we interpret events has consequences for how we think, feel, and behave; these interpretations then act to create and maintain unhelpful responses. The goals of CBT are diverse, ranging from specific symptom reduction, increased insight and understanding of illness, distress reduction, and the development of adaptive coping skills. CBT has more recently been applied to the treatment of psychosis, and comprehensive manuals have been developed (e.g., Hagen, Turkington, Berge, \& Grawe, 2010; Kingdon \& Turkington, 2005). Indeed, CBT is the most widely studied intervention of the three types we review here.

Cognitive models specific to schizophrenia symptoms have also been developed (e.g., Beck \& Rector, 2005; Garety, Kuipers, Fowler, Freeman, \& Bebbington, 2001; Morrison, 2001). Beck and Rector (2005) advanced a cognitive conceptualization of negative symptoms, arguing that negative beliefs about social abilities and performance, as well as lower expectancies for pleasure and success, contribute to the maintenance of negative symptomatology. For example, the belief "I'm going to sound weird, stupid, or strange" may be related to symptoms of alogia or the thought "Why bother, I'm just going to fail" may maintain symptoms of avolition. Kingdon and Turkington (2005) proposed that negative symptoms result from reactions to high levels of stress and a decreased ability to cope. Within this conceptualization, affective flattening is believed to develop from demoralization, alogia is a response to difficulty communicating in reaction to criticism, avolition is driven by the perception of being under pressure and failing to meet expectations, anhedonia results from a sense of hopelessness or numbness, and asociality is a maintaining factor that helps to reduce stress by lowering overstimulation and stressful contexts.

Empirical studies have delineated associations between cognitive distortions and the manifestation and maintenance of negative symptoms as well as functional impairment in schizophrenia. For example, Grant and Beck (2009) found that defeatist beliefs about performance abilities were associated with elevated negative symptoms and poorer functioning. Thus, this cognitive distortion may contribute to the avoidance of meaningful goal related and pleasurable activities. In addition, Grant and Beck (2010) found that asocial beliefs significantly predicted interpersonal communication and prosocial behaviors one year later. Horan et al. (2010) evaluated the relationship between dysfunctional beliefs and negative symptoms, finding that people with higher defeatist performance beliefs also experienced higher negative symptoms and worse community functioning. Taken together, these studies point to an important therapeutic target and suggest that interventions that reduce cognitive distortions, in particular defeatist beliefs, may help to reduce negative symptoms and improve functioning.

\subsection{Empirical findings}

Several reviews (Kern, Glynn, Horan, \& Marder, 2009; Rector \& Beck, 2001; Tarrier \& Wykes, 2004; Turkington, Dudley, et al., 2006; Turkington, Kingdon, et al., 2006) and meta-analyses (Gould et al., 2001; Pilling et al., 2002; Wykes et al., 2008; Zimmermann, Favrod, Trieu, \& Pomini, 2005) suggest that CBT is an effective adjunctive treatment for persistent positive symptoms. However, the benefits of CBT for negative symptoms are less clear. We identified 51 studies that investigated the efficacy of CBT for treating schizophrenia. Of these, 22 were RCTs that reported on negative symptom outcomes (see Table 1). Sixteen of these evaluated individual CBT, four evaluated group CBT, one evaluated a combination of individual and group CBT, and one evaluated group CBT in comparison to social skills training (SST; Lecomte et al., 2008; Lecomte, Leclerc, \& Wykes, 2012), which we discuss in the SST section.

\subsubsection{CBT compared to non-active treatments}

Eight studies compared CBT to a non-active treatment control (e.g., treatment as usual, standard or routine care; wait-list); five provided individual CBT; and three provided group CBT. All of the individual CBT studies found an improvement in negative symptoms either at post treatment or follow-up; one of three group CBT studies found improvement, but only for one of the two samples in the study.

Grant et al. (2012) randomly assigned people to individual cognitive therapy (CT) or TAU. Those who received CT engaged in 18 months of weekly therapy sessions lasting $50 \mathrm{~min}$. TAU varied 
Table 1

Cognitive behavioral therapy (CBT) and negative symptom outcomes.

\begin{tabular}{|c|c|c|c|c|c|c|c|c|}
\hline Citation & $\mathrm{N} /$ diagnosis & Treatment/length of treatment & Control & $\begin{array}{l}\text { Negative Sx } \\
\text { outcome }\end{array}$ & $\begin{array}{l}\text { Raters } \\
\text { blind }\end{array}$ & Results & Follow-up & Effect size \\
\hline $\begin{array}{l}\text { Barrowclough } \\
\text { (2006) }\end{array}$ & $113 / S Z, S A$ & Group CBT/6 months & TAU & PANSS & $\mathrm{Y}$ & No change in NSx & No change 12 months & $\begin{array}{l}6 / 12 \text { months } \\
d=-1.45 /-0.22\end{array}$ \\
\hline $\begin{array}{l}\text { Bechdolf } \\
(2004,2005)\end{array}$ & 88/SZ, RD & Group CBT/8 weeks & Group PE 8 weeks & PANSS & $\mathrm{Y}$ & $\downarrow$ NSx NS group diff & $\begin{array}{l}\text { Maintained at } 6 \text { months } \\
\text { Not maintained at } 24 \text { months }\end{array}$ & $\begin{array}{l}\mathrm{NR} \\
\mathrm{NR}\end{array}$ \\
\hline Borras (2009) & 54/SZ, NP & $\begin{array}{l}\text { Group CBT - self-esteem/12 } \\
\text { weeks (1st sample) }\end{array}$ & $\begin{array}{l}\text { Waitlist } 12 \text { weeks then } \\
\text { treatment (2nd sample) }\end{array}$ & PANSS & NR & $\begin{array}{l}\downarrow \text { NSx CBT only } \\
\text { (1st sample only) }\end{array}$ & $\begin{array}{l}\text { Maintained at } 3 \text { months } \\
\text { (1st sample only) }\end{array}$ & NR \\
\hline Cather (2005) & $30 / \mathrm{SZ}, \mathrm{SA}$ & Individual CBT/16 weeks & Individual PE 16 weeks & PANSS PSYRATS & Y & No change in NSx & - & $\begin{array}{l}\mathrm{CBT} d=-0.10 \mathrm{PE} \\
\mathrm{d}=-0.14\end{array}$ \\
\hline Drury (1996) & 62/ANP & Group and individual CT/12 weeks & Recreation and support group & PAS & $\mathrm{Y}$ & $\downarrow$ NSx NS group diff & Maintained at 9 months & NR \\
\hline Garety (2008) & 301/NAP & $\begin{array}{l}\text { Individual CBT + TAU/individual } \\
\mathrm{FI}+\mathrm{TAU}\end{array}$ & TAU & PANSS & $\mathrm{Y}$ & $\begin{array}{l}\text { No Change in NSx at } \\
12 \text { months }\end{array}$ & No change in NSx at 24 months & $\begin{array}{l}12 / 24 \text { months } \\
\mathrm{d}=-0.87 /-1.32\end{array}$ \\
\hline Grant (2012) & $60 / \mathrm{SZ}, \mathrm{SA}$ & Individual CT/18 months & TAU & SANS & $\mathrm{Y}$ & $\begin{array}{l}\downarrow \text { Avolition-apathy } \\
\text { subscale CBT only }\end{array}$ & - & $\mathrm{d}=-2.16$ \\
\hline Gumley (2003) & 144/SZ, RD & Individual CBT/range (2-16 sessions) & TAU & PANSS & $\mathrm{N}$ & $\downarrow$ NSx CBT only & - & NR \\
\hline Hall (2003) & 25/PD & Individual CBT - self-esteem/7 weeks & TAU & PANSS & $\mathrm{Y}$ & $\downarrow$ NSx CBT only & Maintained at 3 months & NR \\
\hline Jackson (2008) & 62/FEP & Individual ACE/14 weeks & Befriending & SANS & $\mathrm{Y}$ & No change in NSx & No change at 12 months & $\mathrm{d}=-0.40$ \\
\hline $\begin{array}{l}\text { Klingberg } \\
(2009,2011)\end{array}$ & $198 / S Z$ & Individual CBT/9 months & $\mathrm{CR}$ & PANSS & $\mathrm{Y}$ & $\downarrow$ NSx NS group diff & - & $\mathrm{d}=-0.47$ \\
\hline Leclerc (2000) & 99/SZ, SA, PP & Group CBT - coping skills/12 weeks & TAU & PANSS & $\mathrm{Y}$ & No change in NSx & No change at 6 months & NR \\
\hline Lincoln (2012) & 80/SZ, SA, DD, BPD & Individual CBT/4 months & Waitlist & PANSS & $\mathrm{N}$ & No change in Nsx & No change at 12 months & $\begin{array}{l}\text { Post } / 12 \text { months } \\
d=0.14 / 0.28\end{array}$ \\
\hline Rector (2003) & $42 / \mathrm{SZ}, \mathrm{SA}$ & Individual CBT/6 months & TAU & PANSS & $\mathrm{Y}$ & $\downarrow$ NSx NS group diff & Maintained at 6 months CBT only & $\begin{array}{l}\text { Post } / 6 \text { months } \\
d=0.45 / 0.85\end{array}$ \\
\hline $\begin{array}{l}\text { Sensky (2000), } \\
\text { Turkington } \\
\text { (2008) }\end{array}$ & $90 / \mathrm{SZ}$ & Individual CBT/9 months & Befriending & SANS & $\mathrm{Y}$ & $\downarrow$ NSx NS group diff & $\begin{array}{l}\text { Maintained at } 6 \text { months BT } \\
\text { only maintained at } 60 \text { months } \\
\text { CBT only }\end{array}$ & $\begin{array}{l}\mathrm{NR} \\
\mathrm{NR}\end{array}$ \\
\hline Startup (2004) & 90/SZ, SP, SA & Individual $\mathrm{CBT} /$ Mean $=12.9$ sessions & TAU & SANS & $\mathrm{N}$ & No change in Nsx & $\downarrow$ NSx at 12 months CBT only & $\begin{array}{l}\text { Post } / 12 \text { months } \\
\mathrm{d}=0.33 / 0.66\end{array}$ \\
\hline Tarrier (1993) & $27 / S Z$ & Individual CSE/PS/10 sessions & Waitlist & PAS & $\mathrm{N}$ & No change in NSx & No change at 6 months & NR \\
\hline Tarrier (2001) & 72/SZ, SA, DD & Individual CBT/20 sessions & SC, TAU & SANS & $\mathrm{Y}$ & $\downarrow N S x$ & - & NR \\
\hline $\begin{array}{r}\text { Tarrier (2004), } \\
\text { Lewis (2002) }\end{array}$ & 316/SZ, SA SP, DD, Pnos & $\begin{array}{l}\text { Individual CBT/15-20 sessions within } \\
5 \text { weeks }\end{array}$ & SC, TAU & PANSS & $\mathrm{Y}$ & NR & $\downarrow$ NSx CBT and SC at 18 months & $\mathrm{d}=-1.51$ \\
\hline $\begin{array}{l}\text { Turkington } \\
(2002,2006)\end{array}$ & $336 / S Z$ & $\begin{array}{l}\text { Individual CBT/6 sessions within } \\
2-3 \text { months }\end{array}$ & TAU & NSRS & Y & NR & $\downarrow$ NSx CBT only at 12 months & NR \\
\hline $\begin{array}{l}\text { Valmaggia } \\
(2005)\end{array}$ & $62 / S Z$ & Individual CBT/22 weeks & Supportive counseling & PANSS & Y & No change in NSx & No change at 6 months & $\begin{array}{l}\text { Post } / 6 \text { months } \\
d=0.37 / 0.01\end{array}$ \\
\hline
\end{tabular}

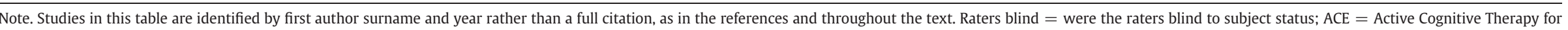

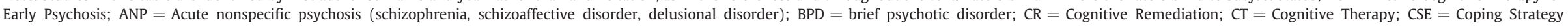

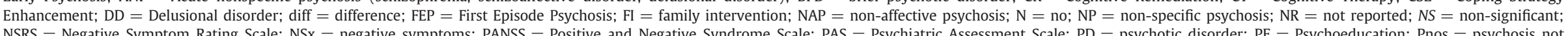

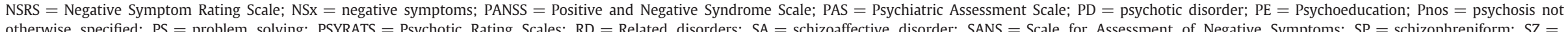

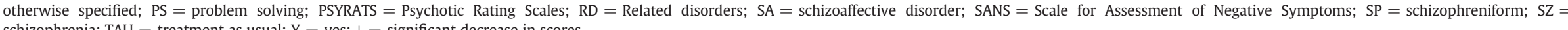
schizophrenia; TAU $=$ treatment as usual; $\mathrm{Y}=$ yes; $\downarrow=$ significant decrease in scores. 
Table 2

Social skills training (SST) and negative symptom outcomes.

\begin{tabular}{|c|c|c|c|c|c|c|c|c|}
\hline Citation & $\mathrm{N} /$ diagnosis & $\begin{array}{l}\text { Treatment/length } \\
\text { of treatment }\end{array}$ & Control & $\begin{array}{l}\text { Negative Sx } \\
\text { outcome }\end{array}$ & $\begin{array}{l}\text { Raters } \\
\text { blind }\end{array}$ & Results & Follow-up & Effect size \\
\hline $\begin{array}{l}\text { Dobson } \\
(1995)\end{array}$ & $28 / S Z$ & Group SST/9 weeks & $\begin{array}{l}\text { Group Milieu } \\
9 \text { weeks }\end{array}$ & PANSS & NR & $\downarrow$ NSx SST only & $\begin{array}{l}\text { Maintained at } 3 \text { months } \\
\text { both groups; Not } \\
\text { maintained at } 6 \text { months } \\
\text { (data for SST only) }\end{array}$ & NR \\
\hline Hayes (1995) & $63 / S Z$ & Group SST/18 weeks & $\begin{array}{l}\text { Discussion group } \\
18 \text { weeks }\end{array}$ & SANS & NR & No change in NSx & No change at 6 months & NR \\
\hline Horan (2009) & $31 / \mathrm{SZ}, \mathrm{SA}$ & Group SCST/6 weeks & $\begin{array}{l}\text { Relapse prevention } \\
\text { group } 6 \text { weeks }\end{array}$ & BPRS: anergia & $\mathrm{N}$ & $\downarrow$ NSx SCST only & - & $\eta^{2}=-0.18$ \\
\hline $\begin{array}{l}\text { Lecomte } \\
\quad(2008,2012)\end{array}$ & $\begin{array}{l}\text { 129/SZspec, } \\
\text { MDP, Pnos }\end{array}$ & $\begin{array}{l}\text { Group SST/group } \\
\text { CBT/3 months }\end{array}$ & Waitlist & BPRS: negative & Y & $\downarrow$ NSx CBT and SST & $\begin{array}{l}\text { Not maintained at } 6 \text { months } \\
\text { or at } 12 \text { months }\end{array}$ & $\begin{array}{l}\eta^{2}=0.25-0.54 \\
\text { follow-up: NR }\end{array}$ \\
\hline $\begin{array}{l}\text { Rus-Calafell } \\
\text { (2013) }\end{array}$ & $31 / \mathrm{SZ}, \mathrm{SA}$ & Group SST/16 sessions & TAU & PANSS & $\mathrm{N}$ & $\downarrow N S x$ SST only & Maintained at 6 months & Follow-up: $\mathrm{d}=0.39$ \\
\hline Sanz (2009) & $14 / S Z$ & Group SCST/10 weeks & TAU & PANSS & NR & No change in NSx & - & NR \\
\hline Xiang (2006) & $96 / S Z$ & Group CRM/8 weeks & Group SC & PANSS & $\mathrm{Y}$ & $\downarrow N S x$ CRM only & Maintained at 6 months & NR \\
\hline
\end{tabular}

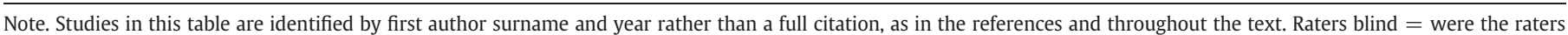

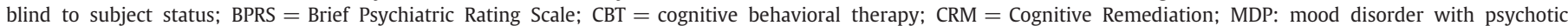

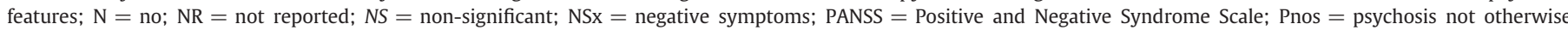

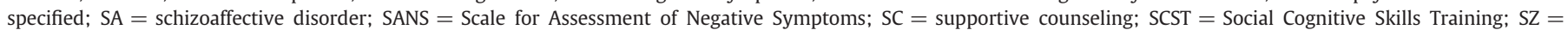
schizophrenia; SZspec $=$ schizophrenia spectrum; TAU $=$ treatment as usual; $\mathrm{Y}=$ yes; $\downarrow=$ significant decrease in scores.

by person, but at a minimum included medications and often composed of common community resources (e.g., case management, day treatment, vocational rehabilitation, etc.). Upon completion of the treatment, those who received CT showed greater improvement on the avolition-apathy subscale of the Scale for the Assessment of Negative Symptoms (SANS; Andreasen, 1982) compared to those who received TAU. Another RCT of CBT (ranging from two to 16 individual sessions) and TAU (access to community mental health, ongoing medication, and routine psychiatric review and follow-up) reported that people who received CBT showed significantly greater improvement on the negative symptom scale of the Positive and Negative Syndrome Scale (PANSS; Kay, Fiszbein, \& Opler, 1987) compared to those who received TAU (Gumley et al., 2003).

Tarrier et al. (2001) compared people randomly assigned to ten weeks of individual CBT, supportive counseling (emotional support and unconditional regard), or TAU (medication management and monitoring through outpatient follow-up and case management). All groups showed an improvement in total SANS scores. However, people who received CBT evidenced a trend for greater improvement compared to TAU ( $p=.07$ ). Furthermore, people who received CBT showed a trend for greater improvement on the alogia subscale ( $p=.06$ ), but not the other subscales, compared to people in supportive counseling group. Hall and Tarrier (2003) compared individual CBT focused on self-esteem with TAU in a small RCT of people recently admitted to an acute psychiatric unit. While hospitalized, TAU consisted of medication, clinical assessment, and routine therapy sessions (e.g., anger management, craft and exercise groups). Upon discharge, TAU included visits from community workers and three monthly outpatient appointments with a psychiatrist. In addition to the TAU services provided to all people, CBT consisted of seven weekly individual sessions where sessions focused on identifying positive qualities and using past and current experiences to increase the belief of these traits. People assigned to receive CBT-self-esteem showed a greater improvement in PANSS negative symptom scores postintervention and at 3-month follow-up than people assigned to TAU.

In an effectiveness study of individual CBT for psychosis (CBTp) in a routine clinical practice setting, Lincoln et al. (2012) found no difference in the post-treatment PANSS negative symptom scores between people who were randomly assigned to four months of CBTp compared to a wait-list control. However, at the one year follow-up, $35 \%$ of the people who completed CBTp evidenced a clinically significant change in negative symptoms (i.e., a reliable improvement) and just over half (55\%) were considered part of the healthy population suggesting a modest effect.
Barrowclough et al. (2006) reported no improvement in the PANSS negative symptom scores of people who were randomly assigned to participate in a six-month group CBT intervention or people who received TAU (medication management, outpatient and community follow-up, and access to community-based rehabilitation programs) at post-treatment or at the 12-month follow-up. An RCT of a 24-session coping skills CBT group compared to TAU (defined as "regular rehabilitation treatment") reported no improvement in PANSS negative symptoms at post-treatment or at six-month follow-up (Leclerc, Lesage, Ricard, Lecomte, \& Cyr, 2000).

In a randomized crossover trial of a 12-week (24 session) group CBT self-esteem intervention, Borras et al. (2009) reported mixed results with only one of the two study samples demonstrating an improvement in PANSS negative symptoms at post-treatment and three months later. Although there was no difference in baseline negative symptom scores between people in the two samples, they received different types of adjunctive care (i.e., some received case management as well, others did not).

\subsubsection{CBT compared to active treatment}

Eight studies compared CBT to an active control treatment; seven provided individual CBT, and one provided a combination of individual and group CBT. Three studies found comparable improvement in negative symptoms in both CBT and the active control, findings that are consistent with a recent meta-analysis of CBT compared to other psychosocial treatments (Jones, Hacker, Corman, Meaden, \& Irving, 2012). However, five other studies found no improvement in either treatment condition.

In a multisite RCT, Klingberg et al. (2009, 2011) compared individual CBT to Cognitive Remediation (CR). CR focused on training attention, memory, and executive functioning using a series of highly structured computer programs. They found a significant improvement on the PANSS negative symptom scale for both CBT and CR treatments, with no between-group differences, suggesting that both interventions were effective. Drury, Birchwood, Cochrane, and Macmillan (1996) found that people randomly assigned to either group and individual cognitive therapy, or recreation and support therapy (an active control designed to match therapist hours and provide structured activities and informal support) showed comparable improvement in negative symptoms as measured by the Psychiatric Assessment Scale (PAS; Krawiecka, Goldberg, \& Vaughan, 1977) after treatment and at the nine month follow-up. Finally, Lewis et al. (2002) randomly assigned people in their first or second acute hospital admission for psychosis to five weeks of individual CBT or supportive counseling (a manualized control 
Table 3

Combined treatments and negative symptom outcomes.

\begin{tabular}{|c|c|c|c|c|c|c|c|c|}
\hline Citation & $\mathrm{N} /$ Diagnosis & $\begin{array}{l}\text { Treatment/length } \\
\text { of treatment }\end{array}$ & Control & $\begin{array}{l}\text { Negative Sx } \\
\text { outcome }\end{array}$ & $\begin{array}{l}\text { Raters } \\
\text { blind }\end{array}$ & Results & Follow-up & Effect size \\
\hline Barrowclough (2001) & $\begin{array}{l}30 / S Z+S U D \\
\text { SA + SUD }\end{array}$ & IIP/9 months & TAU & PANSS & $\mathrm{Y}$ & $\downarrow$ NSx IIP only & $\begin{array}{l}\text { Not maintained } \\
\text { at } 3 \text { months }\end{array}$ & NR \\
\hline Bradley (2006) & 59/SZ, SA, SP & MFG + PE/12 months & TAU & SANS & Y & No change in NSx & - & $\mathrm{NR}$ \\
\hline Buchkremer (1997) & $132 / S Z$ & $\begin{array}{l}\mathrm{PE}+\text { leisure/PE + leisure }+ \text { family } \\
\mathrm{PE} / \mathrm{PE}+\mathrm{CT} / \mathrm{PE}+ \\
\mathrm{C}+\text { family } \mathrm{PE} 8 \text { months } \\
10-20 \text { sessions }\end{array}$ & Leisure group & SANS & $\mathrm{N}$ & No change in NSx & $\begin{array}{l}\text { No change at } 12 \\
\text { or } 24 \text { months }\end{array}$ & NR \\
\hline Daniels (1998) & 40/SZ, SA & Group IBT/8 weeks & Waitlist & SANS & Y & No change in NSx & - & NR \\
\hline Dyck (2000) & 63/PD & $\mathrm{MFG} / 12$ months & TAU & SANS & Y & $\downarrow$ NSx MFG only & - & $\mathrm{NR}$ \\
\hline Girón (2010) & 50/SZ, SP & $\begin{array}{l}\text { Individual FT + individual } \\
\text { counseling + TAU } 2 \text { years }\end{array}$ & $\begin{array}{l}\text { Individual } \\
\text { counseling + TAU }\end{array}$ & WHO-DAS & Y & $\downarrow$ NSx FT group only & - & NR \\
\hline Granholm (2005) & 76/SZ, SA & Group SST + CBT/24 sessions & TAU & PANSS & Y & No change in NSx & - & $\eta^{2}=0.01$ \\
\hline Hansen (2012) & 62/SZspec & CAT + ACT $/ 6$ months & ACT & PANSS & Y & No change in NSx & $\begin{array}{l}\text { No change at } \\
3 \text { months }\end{array}$ & NR \\
\hline Hogarty (1991) & 103/SZ, SA & $\begin{array}{l}\text { Family PE/SST/SST + family } \\
\mathrm{PE} / 24 \text { months }\end{array}$ & TAU & Wing: social withdrawal & $\mathrm{Y}$ & $\begin{array}{l}\downarrow \text { NSx family PE and family } \\
\text { PE + SST only }\end{array}$ & - & NR \\
\hline Hogarty (1997) & $151 / S Z, S A$ & $\mathrm{PT}+\mathrm{FT}+\mathrm{PE} /$ & PT 36 months & Wing & $\mathrm{N}$ & $\begin{array}{l}\downarrow \text { NSx PT }+ \text { FT }+ \text { PE only } \\
\text { at } 18 \text { and } 24 \text { months }\end{array}$ & - & $\begin{array}{l}18 / 24 \text { months } \\
d=0.35 / 0.39\end{array}$ \\
\hline Magliano (2006) & $71 / \mathrm{SZ}$ & $\mathrm{FT}+\mathrm{PE} / 6$ months & Waitlist & BPRS: negative & NR & No change in NSx & - & NR \\
\hline McFarlane (1996) & $68 / S Z, S A, S P$ & $\mathrm{MFG}+\mathrm{PE}+\mathrm{ACT} / 24$ months & $\begin{array}{l}\text { Crisis family intervention } \\
+ \text { ACT }\end{array}$ & PANSS & Y & $\downarrow$ NSx NS group diff; & - & NR \\
\hline Palma-Sevillano (2011) & $34 / \mathrm{SZ}$ & CMT/12 months & TAU & PANSS & Y & $\downarrow N S x$ CMT only & - & $\eta^{2}=0.53$ \\
\hline $\begin{array}{l}\text { Petersen (2005), } \\
\text { Thorup (2005) }\end{array}$ & 547/SZspec & IT/24 months & TAU & SANS & $\mathrm{N}$ & $\begin{array}{l}\downarrow N S x \text { IT only at } 12 \text { and } \\
24 \text { months }\end{array}$ & - & $\begin{array}{l}12 / 24 \text { months } \\
d=0.31 / 0.34\end{array}$ \\
\hline Pinto (1999) & $41 / \mathrm{SZ}$ & CBT + SST/6 months & SC & SANS & NR & $\downarrow$ NSx NS group diff & - & NR \\
\hline Rosenbaum $(2005,2006)$ & 562/SZspec & $\begin{array}{l}\text { Supportive/MFG + ACT + } \\
\text { SST/12-36 months }\end{array}$ & TAU & PANSS & NR & $\downarrow$ NSx NS group diff & $\begin{array}{l}\downarrow N S x \text { both } \\
\text { groups at } 12 \text { and } \\
24 \text { months }\end{array}$ & $\begin{array}{l}\text { NR } \\
\text { NR }\end{array}$ \\
\hline Valencia (2007) & 82/SZ & $\mathrm{FT}+\mathrm{SST} / 12$ months & TAU & PANSS & Y & $\downarrow$ NSx FT + STT only & - & $\mathrm{d}=2.0$ \\
\hline Yildiz (2004) & 30/SZ & SST + Family PE/8 months & TAU & PANSS & Y & $\downarrow$ NSx SST + Family PE only & - & NR \\
\hline
\end{tabular}

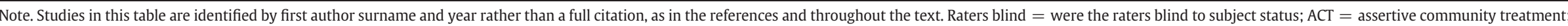

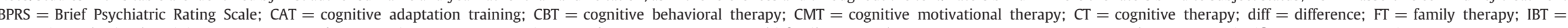

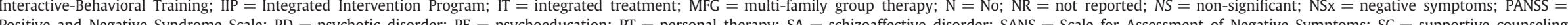

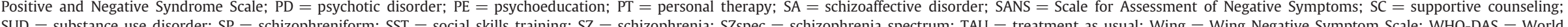

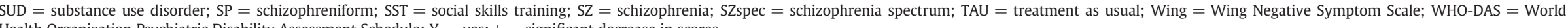
Health Organization Psychiatric Disability Assessment Schedule; $\mathrm{Y}=$ yes; $\downarrow=$ significant decrease in scores. 
therapy matched for therapist exposure) and found that those who received CBT had a significant improvement in overall symptoms at postintervention (negative symptoms results were not reported) compared to those who received TAU (unspecified across participants with the exception that it always included medication and day or inpatient treatment. However, both groups showed similar improvement in PANSS negative subscale scores 18 months following treatment compared to TAU (Tarrier et al., 2004).

Five other studies comparing CBT to and active control treatment found no improvement in negative symptoms. Valmaggia, van der Gaag, Tarrier, Pijnenborg, and Slooff (2005) compared 16 hours of individual CBT to 16 hours of supportive counseling (emotional support and unconditional regard) and reported no significant improvement on the PANSS in either treatment condition. Results from a small RCT of individual functional CBT, a treatment focused on decreasing psychiatric symptoms and improving social functioning, found no improvement in negative symptoms at pre- and post-intervention in either the 16 session treatment condition or the 16 session psychoeducation control group (Cather et al., 2005). The remaining two studies included treatments that diverged slightly from more traditional CBT approaches. Tarrier et al. (1993) randomly assigned people to an individual coping strategy enhancement therapy (CSE; focused on learning skills to monitor symptoms, identify maintaining factors, and develop coping skills to decrease distress), individual problem solving therapy (PS; focused on learning skills to improve cognitive flexibility in an effort to increase problem solving abilities), or a waitlist control. They found no significant improvement on the negative symptom composite score of the PAS and no clinically significant change, as defined by a $50 \%$ or more reduction in an individual's total symptom severity score and an increase in social functioning of at least one standard deviation, in any of the three groups at post-treatment or at the six-month follow-up. Jackson et al. (2008) found no improvement (post-treatment and at one year follow-up) in SANS negative symptom scores for people receiving either individual cognitive therapy or a befriending control condition (Jackson et al., 2008). Garety et al. (2008) found no improvement on the PANSS negative scale at post-treatment or at 24-month follow-up for people receiving either individual CBT or an individual family intervention compared to TAU. However, in a follow-up exploratory analysis, they found that people with caregivers showed improved scores on the PANSS negative scale at 12-months irrespective of whether they received CBT or the family intervention; this was not maintained at 24-months (Garety et al., 2008).

\subsubsection{Do the effects of CBT persist?}

In addition to the five studies reported earlier that suggest maintenance or emergence of negative symptom improvement at follow-up (i.e., Borras et al., 2009; Drury et al., 1996; Hall \& Tarrier, 2003; Lincoln et al., 2012; Tarrier et al., 2004), five additional treatment trials suggest that the effects of CBT persist or emerge beyond the posttreatment assessment. Four trials (Bechdolf et al., 2004; Rector, Seeman, \& Segal, 2002; Startup, Jackson, \& Bendix, 2004; Turkington, Kingdon, \& Turner, 2002; Turkington,Kingdon, et al., 2006) found that CBT was more effective than TAU three to 12 months after treatment, and one trial (Sensky et al., 2000; Turkington et al., 2008) found that CBT was more effective than an active treatment control five years after treatment.

Startup et al. (2004) found no difference in negative symptoms in those randomly assigned to participate in 12-15 90-min. individual CBT sessions or TAU (medication and nursing care during hospitalization and community care after discharge) at post-treatment, but significant improvement in negative symptoms at the 12 month follow-up in those who received CBT. Further, $60 \%$ of the people in the CBT group showed clinically significant change, as measured by a change in an individual's Global Functioning Scale score within two standard deviations of the normative mean, compared to $40 \%$ in the TAU group.
Rector et al. (2002) reported significant improvement on the PANSS negative subscales at post-intervention for people who received 20 -session individual CBT as well as for people who received TAU (comprehensive psychiatric management with medication optimization, clinical case management, and specialized schizophrenia treatment services). However, at the six-month follow-up only those who received CBT maintained continued improvement in PANSS negative symptom scores. Turkington et al. (2002) randomly assigned people to six individual sessions of CBT or TAU (freely determined by their community mental health team) and found that those who received CBT had a significant improvement in overall symptoms at postintervention compared to those who received TAU (negative symptoms results were not reported at post-treatment). However, at one year post-treatment, only people who received CBT showed a significant improvement on the Negative Symptom Rating Scale (NSRS; Hansen, Turkington, Kingdon, \& Smith, 2003) and a clinically significant change of $25 \%$ or more in insight and negative symptoms (Turkington, Kingdon, et al., 2006).

When comparing CBT with active treatment controls, an RCT found a significant improvement in PANSS negative symptom scores in both group CBT (16 sessions) and group psychoeducation (8 sessions) at post-treatment and at a six-month follow-up, with no significant differences between treatment conditions or clinically significant change in individual symptom improvement (Bechdolf et al., 2004). At 24-month follow-up (Bechdolf, Kohn, Knost, Pukrop, \& Klosterkotter, 2005), however, negative symptom scores were no longer significantly different from pre-treatment scores for either group, likely due to the much smaller numbers of people included in this follow-up (i.e., $60 \%$ in CBT and $42 \%$ in psychoeducation lost at 24-month follow-up). An RCT by Sensky et al. (2000) compared 18 individual CBT sessions to a befriending intervention, a control condition designed to match therapist contact time and involved a nondirective and empathetic discussion of neutral topics, and found that both treatments were associated with a significant improvement in the SANS at post-treatment. However, only people who received CBT maintained those improvements and showed clinically significant change, as defined by a $50 \%$ or more reduction in an individual's negative symptom baseline scores at five-year follow-up (Turkington et al., 2008). These studies suggest that while CBT may be as effective as other psychosocial treatments in improving negative symptoms upon treatment completion, people who receive CBT may be more likely to maintain these benefits over time.

\subsection{Summary}

We reviewed 21 CBT studies (one additional study of CBT compared to SST is discussed in the SST section; Lecomte et al., 2008, 2012) that included negative symptoms as a treatment outcome. Over half $(n=12)$ of the studies compared CBT to an inactive control (TAU or waitlist), and the others ( $n=9$ ) compared CBT to another active treatment. Overall, 13 of the 21 studies found that CBT was associated with an improvement in negative symptoms, either at post-treatment or follow-up. Five of the eight studies that did not report improvements in negative symptoms included an active control group (befriending therapy, supportive therapy, psychoeducation, family therapy). Taken together, these studies suggest that individual CBT can be effective for improving negative symptoms. However, the efficacy of group CBT is less clear, in part due to the smaller number of studies that have been conducted. Of the five studies that investigated group CBT, three studies showed evidence of improvement (Bechdolf et al., 2004; Borras et al., 2009; Drury et al., 1996). However, group CBT in two of these studies did not demonstrate benefits above that of other active control treatments. Thus, additional research is needed to confirm its efficacy. This is particularly important because group interventions are often more commonly used in community mental health settings, where most people with schizophrenia receive treatment services. 
Although continued investigation of CBT interventions for negative symptoms is necessary to determine effectiveness, there is room for optimism. CBT is guided by cognitive theory, which has strong empirical support, the results of RCTs for CBT have shown mostly positive shortterm and long-term outcomes and CBT is the only psychosocial intervention reported by PORT treatment recommendations for schizophrenia with some evidence for improving negative symptoms (Dixon et al., 2010). Given the preliminary evidence suggesting that the benefits of CBT persist over time, it is essential that future studies include follow-up assessments in order to fully evaluate the clinical benefits of this treatment approach.

\section{Social skills training}

\subsection{Guiding theory}

Social skills training (SST) for schizophrenia was developed to help people with schizophrenia with difficulties in interpersonal situations and relationships. SST comes from a behavioral model that targets improving a person's ability to function appropriately and skillfully within social interactions, particularly in light of factors that may otherwise make social interactions challenging (e.g., psychotic symptoms, motivational factors, affective states, environmental factors, and neurobiological factors) (Bellack, Muesser, Gingerich, \& Agresta, 2004).

The goal of SST is to help a person gain skills to achieve social competence, which is typically defined by a distinct set of components, including expressive, receptive, and conversation skills, and any other factors that may impact a person's ability to engage in social interactions (e.g., assertiveness skills, situational factors, independent living skills, and medication management; Bellack et al., 2004). Expressive skills include verbal behaviors (including verbal content, form, structure, appropriate vocabulary and amount of speech), paralinguistic behaviors (including the volume, pace, intonation and pitch of speech), and nonverbal behaviors (including appropriate facial expression, eye contact, body language, and proxemics). Receptive skills include the ability to attend to the person with whom you are engaging (including listening, getting clarification, relevance, timing), as well as emotion perception skills (i.e., the ability to accurately perceive the emotions of the person to whom you are attending). Conversational skills include the ability to initiate, maintain, and appropriately end a conversation, as well as building upon receptive skills.

\subsection{Empirical findings}

We identified 21 published articles that investigated the efficacy of SST for treating schizophrenia. Eleven of these were RCTs that reported on negative symptom outcomes (see Table 2). Four studies incorporated SST with at least one other treatment modality (Granholm et al., 2005; Hogarty et al., 1991; Pinto, La Pia, Mennella, Giorgio, \& DeSimone, 1999; Yildiz, Veznedaroglu, Eryavuz, \& Kayahan, 2004), and we thus review these in the next section on Combined treatments. Of the remaining seven studies, five found significant improvement in negative symptoms.

\subsubsection{SST compared to TAU}

One RCT compared group SST, which included modules presented over sixteen sessions that focused on social perception, social information processing, responding and sending skills, affiliative skills, instrumental role skills, interactional skills, and behavior governed by social norms to TAU (Rus-Calafell, Gutierrez-Maldonado, Ortega-Bravo, RibasSabate, \& Caqueo-Urizar, 2013). TAU consisted of individual sessions with a psychiatrist, psychologist, and social worker and provided individual psychotherapy (including CBT), medication management, and family support. Compared to TAU, people in the SST groups showed an improvement in negative symptoms as measured by the PANSS, and this improvement was maintained at six months (Rus-Calafell et al., 2013).

A second, small RCT compared social perception training (learning about emotions, identifying complex social situations) to TAU and found no significant improvement on the PANSS negative symptom subscale for either treatment from pre- to post-treatment, perhaps a reflection of the very small sample size (Sanz et al., 2009).

\subsubsection{SST compared to an active control treatment}

One RCT compared group social cognition skills training (SCST) to a modified version of the UCLA social and independent living skills program, including illness management and relapse prevention; Horan et al., 2009). SCST was developed to improve four domains related to social cognition (facial affect perception, social perception, attributional style, and theory of mind) by the use of instructional videotapes and PowerPoint presentations, didactic learning, as well as modeling and social reinforcement. Over six weeks, people in the SCST group attended one-hour sessions twice a week. Compared to the active control, those who received SCST exhibited an improvement on the Brief Psychiatric Rating Scale (BPRS; Overall \& Gorham, 1962) anergia scale.

Another RCT also compared sixteen sessions of a group community rehabilitation module (CRM) of the UCLA social and independent living skills program with supportive group counseling. Both treatments consisted of groups of six to eight people who met biweekly. Following treatment, people in the CRM group showed a significant improvement in negative symptoms as assessed by the PANSS than those in supportive counseling; this effect persisted at the six-month follow-up (Xiang et al., 2006).

Lecomte et al. (2008) randomly assigned people to group CBTp, SST, or a wait-list control. The CBTp and SST groups met twice a week for 24 weeks over the course of eight months. They found that people in both active treatment groups (CBTp and SST) had significantly improved scores on the BPRS negative symptom scale at post-treatment, but not at the six-month follow-up. At the one-year follow-up, people who received CBTp tended $(p=0.06)$ to maintain the improvements in negative symptoms (Lecomte et al., 2012).

An RCT by Dobson et al. (1995) compared group SST with Milieu therapy (i.e. choice of structured activities, including discussion groups). Over the course of nine weeks, the SST group met weekly for four one-hour sessions; the Milieu therapy group was more flexible, but activities were available for the same length of time as the SST condition. Symptoms were assessed via the PANSS pre-treatment, at three-week intervals throughout nine weeks of treatment, and at three- and sixmonth follow-ups; six-month follow-up data was only available for participants in the SST group. At post-treatment, people who received SST had a greater improvement in negative symptoms than those receiving Milieu therapy. However, this group difference did not persist at the three-month follow-up and neither group showed an improvement from pre-treatment at the six-month follow-up.

Finally, one RCT comparing SST to an active control treatment did not find a significant improvement in negative symptoms. This RCT compared eighteen weeks of SST to a discussion group. The discussion group focused on interpersonal relationships and purposeful use of time, but did not explicitly teach or demonstrate social skills. Neither group evidenced an improvement in negative symptoms on the SANS immediately post-group and at six-month follow-up (Hayes et al., 1995).

\subsection{Summary}

We reviewed seven RCTs of SST that reported negative symptom outcomes. Two studies compared SST to TAU and the remaining studies compared SST to an active control. Overall, five of these studies found that SST was associated with an improvement in negative symptoms post-treatment. Four of these studies also assessed negative symptoms at follow-up; two studies reported that these gains were 
maintained at six-month follow-up (Rus-Calafell et al., 2013; Xiang et al., 2006), one study reported that gains were maintained at the three-month follow-up, but not at six-months (Dobson et al., 1995), and one reported that gains were not maintained at six-month follow-up (Lecomte et al., 2008). Although SST was not initially conceptualized as a treatment for negative symptoms, taken together, these studies suggest that SST can be effective for improving negative symptoms in the short-term.

\section{Combined treatments}

This section includes studies of combined treatment packages in which two or more interventions are provided together and not tested separately so there is no way to tell if either one was more effective than the other. Many of these studies include family therapy and/or psychoeducation as components of the treatment package, and so some background on these two approaches will be provided. We also found additional CBT and SST studies that were combined with another treatment, and include them in this discussion as well.

\subsection{Guiding theory: family therapy}

Family therapy focuses on examining and changing existing patterns and dynamics between members of a family, which can be defined as a couple, nuclear family, extended family, or the relationship between a family and other interpersonal systems (Wynne, 1988). These patterns are believed to play a role in the creation and maintenance of problematic behaviors, including those that affect interpersonal relationships as well as the various symptoms associated with psychological disorders. Many types of family therapy are based in systems theory, which postulates that it is impossible to understand the individual without understanding the dynamics and relationships in their interpersonal environment (Doherty \& McDaniel, 2010).

The primary goal of family therapy in schizophrenia is to focus on changing family relationships and interpersonal interactions as a way to facilitate symptom alleviation and recovery (Doherty \& McDaniel, 2010) This typically involves engaging the family in treatment as early as possible, education regarding the disorder, recommendations for coping, communication training, problem-solving training, and crisis intervention; it may or may not include the addition of a specific psychoeducational family program (Goldstein \& Miklowitz, 1995). Communication deviance, or the extent to which a person is unable to establish and maintain a shared focus of attention with a listener, is often a key outcome in family therapy studies in schizophrenia. Studies have indicated that the parents of young adults with schizophrenia have higher levels of communication deviance than do parents of young adults with other disorders (Miklowitz et al., 1986). Because family therapy in schizophrenia often includes psychoeducation, distinguishing the two approaches is often not possible.

\subsection{Guiding theory: psychoeducation}

Psychoeducation is derived from the diathesis-stress model (Zubin \& Spring, 1977), a model that focuses on the interaction between a predisposition toward disease - the diathesis - and environmental, or life, disturbances - the stress. Education and information about potentially stressful or triggering behaviors, attitudes or responses can help people avoid creating the types of situations that would exacerbate the likelihood of relapse symptom exacerbation (Lefley, 2009). Psychoeducation for schizophrenia includes sessions - usually in groups - during which people are given pertinent information about the disorder, including information about symptoms, how to distinguish symptoms from personality, the importance of medication, accepting a vulnerability to future episodes, the role of stressful life events in triggering symptoms and episodes, as well as how to recognize triggering behaviors, attitudes, and responses (Goldstein \& Miklowitz, 1995).

\subsection{Empirical findings}

We identified 58 combined treatment studies that included some combination of family therapy, psychoeducation, CBT, or SST. Eighteen of these were RCTs that reported on negative symptom outcomes (see Table 3). Of these, 12 reported improvements in negative symptoms.

\subsubsection{Combined treatments with family therapy}

We identified three studies of either individual or multi-family group therapy in combination with another treatment modality that was compared to TAU alone (Bradley et al., 2006; Petersen et al., 2005; Valencia, Rascon, Juarez, \& Murow, 2007), and three others that compared family therapy in combination with another treatment to an active treatment control group (Hansen, Østergaard, Nordentoft, \& Hounsgaard, 2012; Hogarty et al., 1997; McFarlane, Dushay, Stastny, Deakins, \& Link, 1996). We also identified two studies that compared individual (Girón et al., 2010) or multi-group family therapy (Dyck et al., 2000) to TAU. Despite the fact that these studies were not combined treatments per se, we include them here because they are the only two from which the effects of family therapy can be disentangled from the effects of other treatments; both suggest that multi-group family therapy can be beneficial for negative symptoms. Two other studies incorporated a family therapy component with CBT or psychoeducation (Barrowclough et al., 2001; Magliano et al., 2006) and will be discussed in the Combined treatments with psychoeducation and Combined treatments with SST or CBT sections, respectively.

An RCT by Valencia et al. (2007) compared 48 weekly sessions of social skills training plus family therapy to TAU, which included medication management and 20-min. monthly appointments. People who received the combined social skills and family therapy had significant negative symptom improvement as assessed by the PANSS compared to people who received TAU. In contrast, Bradley et al. (2006) did not find significant improvement in negative symptoms on the SANS between a multiple-family-group combined with psychoeducation to TAU over the course of 12 months.

A 2005 RCT compared two years of an integrated therapy (IT) with TAU in participants with a first episode of psychosis (Petersen et al., 2005; Thorup et al., 2005). IT consisted of assertive community treatment (ACT), social skill training, and multifamily groups, whereas TAU involved "typical treatment" in community health centers. At the oneand two-year assessments, people who received IT had significantly greater improvement on the SANS compared to people who received TAU (Petersen et al., 2005); at the two-year assessment people receiving the combined treatment also had significantly greater improvement on the affective flattening, alogia, avolition/apathy, and anhedonia/asociality subscales of the SANS (Thorup et al., 2005).

Hansen et al. (2012) compared IT (Petersen et al., 2005; Thorup et al., 2005) plus cognitive adaptation training and assertive communication treatment (ACT) to IT plus ACT. Cognitive adaption training involves providing supports (e.g., signs, checklists, alarms) to deal with cognitive problems (e.g. forgetting). Assertive community training is an intensive, integrative approach that provides most psychiatric services in people's living environments rather than in an office or clinic (Mueser, Bond, Drake, \& Resnick, 1998). Neither group showed an improvement in negative symptoms on the PANSS post-treatment or at the three-month follow-up.

Another RCT compared the efficacy of MFG plus ACT to ACT + a crisis family intervention over the course of two years (McFarlane et al., 1996). Crisis family intervention involved interactions with treatment providers only when a family crisis arose. Both groups exhibited significant improvements in negative symptoms as assessed by the PANSS, with no significant differences between groups.

Hogarty et al. (1997) randomly assigned people to either personal therapy (PT), which focused on affective regulation and personal/social adjustment, or PT plus family therapy over the course of three years. Participants who lived with a family member were assigned to receive 
PT plus family therapy, which also included family psychoeducation. Compared to people who received PT alone, people who received PT plus family therapy showed significant improvements in negative symptoms on the Wing Negative Symptom Scale (Wing, 1961). Most of the treatment effects occurred in the second and third years of therapy, suggesting that longer interventions may be needed.

The two studies comparing multifamily group therapy (MFG) to TAU found that MFG was superior. Girón et al., 2010 compared 24 months of MFG to TAU. The family intervention was integrated with a six-session module to teach empathy. For the first nine months the group met every other week. After nine months, the group met monthly for the next fifteen months. TAU consisted of support, home visits, social work, medication, and individual therapy that included psychological support and problem-solving. People who received MFG had a significant improvement in negative symptom as assessed with the Spanish version of the World Health Organization Psychiatric Disability Assessment Schedule (WHO-DAS; WHO, 1988) compared to people receiving TAU.

Dyck et al. (2000) randomly assigned people to MFG or TAU. MFG consisted of weekly sessions that included both people with schizophrenia and their families, biweekly sessions that only included the family as well as TAU. TAU involved meetings with a case manager, nurse, psychiatrist, and social worker for medication and case management, along with unspecified "therapeutic and rehabilitative" services. Post-treatment, people who received MFG had significantly improved scores on the SANS global score, compared to people who received TAU alone.

\subsubsection{Combined treatments with psychoeducation}

We identified three studies that combined psychoeducation with least one other treatment modality (Buchkremer, Klingberg, Holle, Schulze Mönking, \& Hornung, 1997; Magliano et al., 2006; Rosenbaum et al., 2005, 2006). One of these studies found a significant improvement in negative symptoms for a combined treatment involving psychoeducation.

A multi-site, partial RCT (random assignment to groups for twothirds of the study sample) compared the effects of two active treatment conditions to TAU, in people with a first episode of psychosis (Rosenbaum et al., 2005, 2006). The first active treatment condition was individual or group supportive therapy; the second was assertive community training (ACT) plus multi-family psychoeducational group therapy. TAU was not standardized across participants, but consisted of psychological interventions, medication, and treatment administered according to individual needs and available resources. Compared to people who received TAU, people who received either active treatment exhibited an improvement on the PANSS negative symptom scale after one year (Rosenbaum et al., 2005). Furthermore, at the two-year follow-up that included $80 \%$ of the original participants, negative symptoms continued to improve on the PANSS negative symptoms scale in both active treatment groups (Rosenbaum et al., 2006).

An RCT by Buchkremer et al. (1997) compared four different, active combined treatment conditions to a control group. Each active combined treatment included at least two different treatments: 1) Psychoeducational medication management training and leisuretime group, 2) Psychoeducational medication management training, leisure-time group, and family psychoeducation, 3) Psychoeducational medication management training and cognitive therapy, and 4) Psychoeducational medication management training, cognitive therapy, and family psychoeducation. The control treatment group was a leisure-time group alone. To investigate treatment outcomes, the authors opted to combine the four active treatment groups to compare with the control. They found no significant improvement in negative symptoms on the SANS for all active treatments combined, and no significant difference between the combined active treatment group compared to the control condition at post-treatment or at the 12- and 24-month follow-up.
Finally, Magliano et al. (2006) compared a psychoeducational family intervention to a waitlist control. The psychoeducational family intervention included assessing needs, informational sessions for people with schizophrenia and their family, as well as communication and problem-solving skills training. The treatment involved at least three hourly sessions per month for six months; frequency and location of those meetings was individually determined. There was no significant difference between groups or a significant improvement on the BPRS negative subscale post-treatment (Magliano et al., 2006).

\subsubsection{Combined treatments with SST or CBT}

We identified seven studies that combined CBT and/or SST with at least one other treatment modality (Barrowclough et al., 2001; Daniels, 1998; Granholm et al., 2005; Hogarty et al., 1991; PalmaSevillano et al., 2011; Pinto et al., 1999; Yildiz et al., 2004). Four of these studies found that the combined treatment approach was associated with a greater improvement in negative symptoms compared to either TAU; one study found that the combined treatment and the control treatment (supportive therapy) were associated with an improvement in negative symptoms, and two did not find any negative symptom improvements.

An RCT by Hogarty et al. (1991) compared social skills training alone, family psychoeducation alone, and family psychoeducation plus social skills training combined to TAU (medication and supportive therapy) over 24 months. They found that people in both family conditions (family psychoeducation alone and family psychoeducation plus social skills training) showed an improvement on the social withdrawal scale of the Wing Negative Symptom Scale post-treatment compared to TAU. Barrowclough et al. (2001) randomly assigned people to either an Integrated Intervention Program (IIP; consists of motivational therapy, CBT, and family support) or to TAU (psychiatric management via case management and medication, monitoring via outpatient and community follow-ups, and access to community-based rehabilitation facilities). Those who received the combined treatment had improved negative symptom scores on the PANSS compared to those who received TAU. However, these improvements were not maintained at the threemonth follow-up.

In another small RCT, Yildiz et al. (2004) compared SST plus family psychoeducation to TAU. Those who received the combined treatment met twice a week, and their family attended sessions every two weeks, while those who received TAU received discussion of treatment issues and monthly meetings with a psychiatrist. Following treatment, those who received the combined treatment had improvements in negative symptoms according to the PANSS negative scale compared to baseline as well as compared to those who received TAU. An RCT compared cognitive motivational therapy to routine care (Palma-Sevillano et al., 2011). The cognitive motivational therapy was a combination of psychoeducation, individual CBT, family intervention, and motivational intervention. Routine care included pharmacological treatment. After six months of treatment, people who received cognitive motivational therapy had significantly greater improvement on the PANSS negative scale compared to people who received routine treatment. Finally, Pinto et al. (1999) randomly assigned people to individual treatment of either combined CBT plus SST or to supportive therapy. For people in the CBT plus SST group, the frequency and duration of therapy was based on treatment needs. Although people in both treatments exhibited improvement on the SANS at post-treatment, there were no significant differences between CBT plus SST compared to supportive therapy.

Two studies combining either CBT or SST (or both with each other) did not find improvements in negative symptoms. An RCT by Granholm et al. (2005) compared a combined group treatment of CBT plus SST to TAU. People in CBT plus SST group met weekly for two-hour sessions over the course of 24 weeks. TAU was not standardized across participants, although $82 \%$ reported medication visits and 19\% reported engaging in some type of psychotherapy in the six weeks prior to the 
study. People who received CBT plus SST showed no improvements in PANSS negative symptoms from pre- to post-treatment and compared to those who received TAU. Daniels (1998) found no differences in SANS negative symptom scores post treatment between people randomly assigned to a group that combined social skills and cognitive behavior techniques (two 50-min. sessions per week over the course of eight weeks) or to a waitlist control.

\subsection{Summary}

Studies that combine more than one treatment have the potential to elucidate whether individual treatments are efficacious as well as potential additive benefits of combining treatments. To do so, however, the design must compare the two (or more) treatments individually to the combination of those treatments. Only two studies specifically compared the efficacy of combined treatments to the individual treatments that comprised the combination, rather than comparing the combination to a TAU or waitlist condition (Hogarty et al., $1991,1997)$ and both found that the combined treatment was associated with a greater improvement in negative symptoms. The other studies compared combination treatment conditions to a control condition (e.g., TAU, supportive therapy, another combined treatment, or a waitlist condition); thus, it is impossible to interpret whether the combined treatment approach provides additional benefits above and beyond the benefits of the individual treatment packages.

Practically speaking, there are reasons to think that family therapy might help with negative symptoms. By virtue of the fact that the family is involved in treatment, the person with schizophrenia may be receiving more social support than in an individual treatment, and therefore more opportunities to engage in social activities and behaviors. As such, people with schizophrenia may feel more connected and may be better able to develop feelings of social connectedness. Indeed, the two studies that looked at family therapy alone found an improvement in negative symptoms (Dyck et al., 2000; Girón et al., 2010). Furthermore, eight of the eleven studies that included some type of family component demonstrated an improvement in negative symptoms. However, it may also be the case that people who have family members who are willing to be involved in treatment may represent a subgroup of people with schizophrenia who are more amenable to psychosocial interventions and have a greater support network to assist with treatment.

Most of the studies (fourteen of the eighteen reviewed here) did not include follow-up assessments and thus it remains unclear whether symptom improvements persisted longer-term. One study with a duration of three years (Hogarty et al., 1997) indicated that improvements in negative symptoms did not occur until the second and third year of therapy, while a second study (Petersen et al., 2005; Thorup et al., 2005) indicated improvements in negative symptoms at 12 and 24 months; this potentially indicates that longer interventions are needed. Finally, many of the studies that made claims about negative symptoms in the results utilized outcome measures that assessed social functioning rather than negative symptoms. Measures of social functioning do not necessarily capture or indicate improvement in the negative symptoms broadly or in asociality specifically.

Adding psychoeducation does not appear to be associated with an improvement in negative symptoms, at least in the three studies that incorporated psychoeducation and assessed negative symptoms where just one found a reduction in negative symptoms. However, the impact of psychoeducation specifically on negative symptoms was not directly tested; psychoeducation was only provided along with other treatments, and never as a standalone treatment. Thus, the efficacy of psychoeducation, whether alone or in combination with other treatments, remains an important avenue for future research.

In sum, despite the fact that two-thirds of the studies reviewed here indicated improvement in negative symptoms post-treatment, it is difficult to ascertain whether this can be attributed to the addition (or combination) of different therapies. Additional research is needed to first elucidate which of these components are effective, and then test whether there is an additive effect when combining these components, and whether these effects persist over time. To address these issues, researchers should utilize longitudinal designs, test the efficacy of these treatments in and of themselves as well as in combination with each other, and include standardized negative symptom rating scales.

\section{General discussion}

Although psychosocial treatment modalities appear promising for improving negative symptoms, there are many unanswered questions about how best to intervene. Of the interventions reviewed, CBT and SST appear to have the most empirical support. Indeed, two-thirds of the CBT and nearly three-quarters of SST studies found an improvement at post-treatment, follow-up or both. However, there are twice as many RCTs for CBT as SST (either alone or in combination with another treatment), and only one of these studies examined an intervention designed to specifically target negative symptoms. While the combined treatment approach also shows promise, it remains unclear if combined treatments provide improvements above and beyond those associated with each individual treatment modality.

Our review suggests preliminarily that CBT and SST may differ in their efficacy at follow-up. That is, 64\% (9/14) of CBT studies that re-assessed negative symptoms at follow-up (ranging from 3- to 60-month follow-up) reported maintenance of negative symptom improvement, while $40 \%(2 / 5)$ of SST studies that re-assessed negative symptoms at follow-up (only a six-month follow-up in both studies) reported similarly maintained gains. Differences between the CBT and SST trials may help account for this potential difference. First, even though the two treatment types did not differ in average treatment length, the range of treatment lengths differed between SST (ranging from 9 weeks to 24 months, with a mean of 8.75 months) and CBT (ranging from 2 to 18 months, with a mean of six months) as did the timing of follow-up assessments. Three of the five SST studies included a follow-up at either three or six months post-treatment. In contrast, of the 14 CBT studies that reported on follow-up data, 13 of them included follow-up from six months to five years post-treatment, while only two reported on short-term follow-up at three months. Additional research is needed to examine whether the duration of treatment is a factor in sustaining a longer-lasting improvement in negative symptoms.

A second consideration is that CBT and SST differ in structure and format. Every SST treatment was conducted in a group setting, while CBT was more often an individual treatment. By providing individuals with the opportunity to engage socially without expending much effort to do so (e.g. having a social context provided rather than having to seek out social situations), it is unclear whether these improvements in social behavior and negative symptoms would extend beyond the treatment setting. On the other hand, providing a social context for treatment may be an "active" ingredient of SST, and people with schizophrenia who successfully attend such group treatments may thus benefit by virtue of their joining in with a group of people. Interestingly, three studies also found that group CBT was at least partially effective at improving negative symptoms (Bechdolf et al., 2004; Borras et al., 2009; Drury et al., 1996).

Another difference between CBT and SST is of course the treatment content. The goal of SST is to improve social functioning through learning "externalized" skills (e.g., expressive, receptive, and conversation skills), whereas CBT focuses more on interpreting and responding to internal experiences (e.g., thoughts and feelings). This difference may have implications for the continued practice of learned skills and improved outcomes after treatment ends. For example, those who participate in SST must continue to involve themselves in social situations in order to hone the social skills they have learned in treatment. This may 
be difficult for some people with schizophrenia given available social, financial, or logistical resources. However, in the case of CBT, people can continue to practice many of these skills without external cues or resources. Furthermore, CBT theory suggests that change helps to modify negative core beliefs or schemas about the self, the world, and others, which in turn contributes to more long-lasting change (Beck, 2011). Regardless, differences in treatment content suggest potential mechanisms for change. For example, are there ways to increase the likelihood of improvement earlier in the course of treatment that in turn may persist for longer? It would be interesting for future studies to compare these two interventions, making sure not only to keep the intervention format consistent across treatment types, but also to include more extended follow-up data so that long-term benefits can be assessed.

Significant methodological issues must be addressed in future research of combined treatments, and conclusions about their efficacy or effectiveness cannot be clearly made. At best, the findings suggest that the addition of family therapy may be beneficial. Although people with schizophrenia who enroll in family therapy studies may represent a specific subset of this population with unique characteristics (e.g., family support and engagement), they appear to benefit from added support and external sources of motivation. Of the eleven studies reviewed that involved family therapy, eight were associated with an improvement in negative symptoms.

\section{Future directions}

Given the relative dearth of effective psychosocial treatments for negative symptoms in schizophrenia, it is not surprising that efforts to develop new treatments have increased in recent years. Though these newer treatments have not been as extensively studied, the preliminary findings are promising.

\subsection{New wave of treatments}

Several studies have begun to investigate novel psychosocial interventions, and preliminary evidence suggests that some may be beneficial for improving negative symptoms. However, these interventions need to undergo a more rigorous evaluation to determine their efficacy and effectiveness. ${ }^{2}$

To date, studies of Cognitive Remediation Training (CRT), computerbased or paper and pencil-based interventions designed to enhance basic cognitive abilities (e.g., attention, memory) do not seem to be effective in improving negative symptoms (Dickinson et al., 2009; Hodge et al., 2010; McGurk, Mueser, DeRosa, \& Wolfe, 2009; Wykes et al., 2007). However, combining CRT with a social component (e.g., social cognition skills, problem-solving, group format) may be helpful for improving negative symptoms. For example, an RCT of Cognitive Enhancement Training (CET), a multi-modal interventions including computer-based training and social skills training, reported that compared to supportive therapy people with early-course schizophrenia or schizoaffective disorder showed significant improvements in negative symptoms, as measured by the Wing Negative Symptom Scale at post-treatment (Eack et al., 2009) and two years later (Eack, Mesholam-Gately, Greenwald, Hogarty, \& Keshavan, in press). Further, an RCT of problem solving and Cognitive Flexibility Training (Farreny et al., 2012), which is a group treatment targeting cognitive abilities and general functioning, reported that people who completed 32 group sessions showed greater improvement in PANSS negative

\footnotetext{
${ }^{2}$ Other treatments that have assessed negative symptom outcomes but with only 1 or 2 RCTs include, art therapy (Crawford et al., 2012; Richardson, Jones, Evans, \& Rowe, 2007), music therapy (Ulrich, Houtmans, \& Gold, 2007), dance therapy (Rohricht \& Priebe, 2006), occupational therapy (Cook, Chambers, \& Coleman, 2009), vocational rehabilitation (Bio \& Gattaz, 2011), and dog-assisted group integrated psychological therapy (Villalta-Gil et al., 2009).
}

symptom scores than people who completed a leisure control group (e.g., card games, board games, "coffee $\&$ talk").

We found two small, uncontrolled studies of interventions that were explicitly designed to target negative symptoms. First, Favrod, Giuliani, Ernst, and Bonsack (2010) found that after 10-25 h of Cognitive-Sensory Training (CST), a skills-based intervention to directly target deficits in anticipatory pleasure and anhedonia, there was a significant improvement on the anticipatory pleasure subscale of the Temporal Experience of Pleasure Scale (Gard et al., 2007), as well as an increase in both the number and complexity of activities in which people participated, suggesting that this intervention not only improved anticipatory pleasure deficits, but that these improvements were also associated with increased functioning. Second, an open trial of Loving Kindness Meditation (LKM), an intervention that teaches skills in concentration meditation and focuses on mindfully directing compassion and warmth toward the self and others as a tool for increasing positive emotions and resources, found that people with schizophrenia reported an increase in positive emotions, self-acceptance, satisfaction with life, and an improvement in negative symptoms after participating in six meditation sessions, and these benefits remained at a three-month follow-up (Johnson et al., 2011), suggesting that interventions focused on increasing personal resources and well-being may help to improve negative symptoms.

\subsection{Standardization of study measurement and design}

What has become clear from the current review is the need for standardization in negative symptom assessment, treatment implementation, and follow-up time points, as well as replication of interventions that have shown efficacy in improving negative symptoms.

First, more than half of the initial studies identified for this review did not report on negative symptoms, and thus future studies should include and report assessments of negative symptoms in order to further assess whether a psychosocial treatment is helpful for these symptoms. Of the studies that did report on negative symptoms, the lack of a standard negative symptom measure(s) makes it difficult to draw conclusions about efficacy across studies. Further, the most widely used measures of negative symptomatology (PANSS and SANS) include items that are not considered to be part of the negative symptoms construct (e.g., attentional impairment, difficulty in abstract thinking, stereotyped thinking) and rely more heavily on behavioral aspects of negative symptoms (e.g. blunted affect, social activity), placing less emphasis on experiential or motivational components (e.g. internal desire or experienced emotion). This is problematic because behavioral deficits may result from factors unrelated to negative symptoms, including financial or social constraints. Furthermore, while deficits in behavior may exist (e.g., blunted affect, decreased social interactions, decreased speech production), internal experiences may remain intact (e.g., desire to be around family, interest in recreational activities, pleasure from interacting with others). Thus, ratings gained from current negative symptom assessments that rely heavily on behavior may result in elevated negative symptom scores in instances where these scores are not warranted because internal experiences are not considered (Blanchard, Kring, Horan, \& Gur, 2011; Horan et al., 2011). Using negative symptom assessments that measure each of the five agreed upon symptom domains and systematically measures experience and behavior, such as the Clinical Assessment Interview for Negative Symptoms (Kring et al., 2013) or the Brief Negative Symptom Scale (Kirkpatrick et al., 2011), will provide a more comprehensive measure of negative symptoms.

Second, in order to compare, learn from, and improve treatments for negative symptoms, it is necessary to replicate previous findings using the same manualized treatment and to standardize the method of implementation of these interventions (e.g., number of sessions, length of sessions, group vs. individual sessions, content discussed, etc.). Of course, these aspects may differ based on the type of treatment, 
but it is difficult to compare the efficacy of any treatment modality given the huge variation in treatment protocols. If manualized treatments are used, studies should measure and report treatment fidelity in order to monitor, enhance, and ensure the accurate administration of the intervention. Unfortunately, only 22 of the 46 studies included in this review did so, and measures of treatment fidelity varied across studies (e.g., adherence checklists, sessions coded by raters, etc.). There is also a need to assess which components of various treatments are useful and for whom. If treatments are combined, studies should include groups with random assignment to the individual treatment components alone in order to determine if the combined approach provides additional benefits. There is also variation in the definition of TAU across studies, making improvement or the lack thereof difficult to interpret across studies. Finally, it may also be the case that existing psychosocial treatments be further adapted so as to take into account cognitive deficits, at least with those people who have more severe deficits. In other words, some treatments may need to be simplified, longer in duration, and include greater repetition of treatment modules.

Third, future studies should include common follow-up assessment time-points and track the continued use of therapy skills across time. As discussed, it is necessary for treatment trials to include follow-up assessments at least 12 months post-treatment and longer in order to track longer-term outcomes. Furthermore, tracking the use of therapy skills, both during treatment and after treatment is completed, will provide additional insight into whether continued practice is necessary to maintain outcomes. The ability to measure, report, and compare the practice of treatment skills may help to explain differences in shortterm and long-term outcomes across treatment modalities and provide evidence for the practical application of these interventions in a community setting. That is, if continued practice of skills is necessary to see change, but consumers are unlikely to engage in these behaviors, is the treatment feasible and beneficial?

Finally, even when statistically significant changes in negative symptoms are reported, this information provides little insight into individualized improvement. Thus, future studies should include clinically meaningful change as an outcome measure (Jacobson \& Truax, 1991). In order to include measures of clinically significant change, studies must define clinical change a priori and report these outcomes in addition to statistical change. Only seven studies included in our review reported clinically significant change metrics for negative symptoms (all investigating CBT), with four finding clinically significant change (Lincoln et al., 2012; Startup et al., 2004; Turkington, Kingdon, et al., 2006; Turkington et al., 2008) and three finding no clinically significant change (Bechdolf et al., 2004; Lecomte et al., 2008; Tarrier et al., 1993).

\subsection{Additional considerations in treatment development}

Although motivation for change is a common a barrier to treatment across psychological disorders and treatment modalities, deficits in motivated behavior are part of the negative symptom construct and may make it particularly challenging for people with negative symptoms to engage in treatment. That is, the very people we are designing treatments for may never make it to our office because the symptoms we are trying to improve may be a barrier to treatment engagement. Yet, over three-quarters of studies reviewed here reported dropout rates of $20 \%$ or lower, suggesting that after the initial hurdle of beginning treatment people with schizophrenia and negative symptoms are able to persist in treatment. Future studies should continue to report on dropout rates in order to more systematically evaluate the extent to which avolition is a treatment barrier.

Little is known about how comorbid disorders (e.g., anxiety, depression, substance use) may further complicate interventions for negatives symptoms (as in Barrowclough et al., 2001). For example, if a person has social anxiety, group treatments may be avoided, not because of lack of motivation, but because of discomfort around others. Thus, common comorbid conditions that may present a potential treatment barrier should be assessed and reported in order to determine if these treatments are ineffective because they are not helpful for negative symptoms or because other conditions or symptoms prevent the person for engaging and benefitting from treatment. If the latter is the case, we may unjustly rule out potentially beneficial negative symptom treatments.

Furthermore, there are likely groups and subgroups for which various treatment components will work to greater or lesser extents. While including people with complex or comorbid disorders may better represent people seeking services from community mental health centers, efficacy studies should report on outcomes between diagnostic and symptom groups to discover which treatments work best for which subgroups. After initial efficacy for a treatment approach is established, future studies should extend the treatment to examine its effectiveness in a community sample. Finally, as future directions become current directions, it is also necessary to find better ways of disseminating these findings, assessment measures, and treatments to the broader community of researchers, clinicians, support persons and family, as well as to those people with schizophrenia.

\section{References}

American Psychiatric Association (2004). Practice guideline for the treatment of patients with schizophrenia. Arlington, VA: American Psychiatric Association.

American Psychiatric Association (2010). DSM-5: The future of psychiatric diagnosis. Washington, DC: American Psychiatric Association (http://www.dsm5.org).

Andreasen, N. C. (1982). Negative symptoms in schizophrenia. Archives of General Psychiatry, 39, 784-788.

Barrowclough, C., Haddock, G., Lobban, F., Jones, S., Siddle, R., Roberts, C., et al. (2006) Group cognitive-behavioural therapy for schizophrenia: Randomised controlled trial. The British Journal of Psychiatry, 189, 527-532.

Barrowclough, C., Haddock, G., Tarrier, N., Lewis, S., Moring, J., O'Brien, R., et al. (2001) Randomized controlled trial of motivational interviewing, cognitive behavioral therapy, and family intervention for patients with comorbid schizophrenia and substance use disorders. The American Journal of Psychiatry, 158, 1706-1713.

Bechdolf, A., Knost, B., Kuntermann, C., Schiller, S., Klosterkotter, J., Hambrecht, M., et al. (2004). A randomized comparison of group cognitive-behavioural therapy and group psychoeducation in patients with schizophrenia. Acta Psychiatrica Scandinavica, 110, 21-28.

Bechdolf, A., Kohn, D., Knost, B., Pukrop, R., \& Klosterkotter, J. (2005). A randomized comparison of group cognitive-behavioural therapy and group psychoeducation in acute patients with schizophrenia: outcome at 24 months. Acta Psychiatrica Scandinavica, 112(3), 173-179. http://dx.doi.org/10.1111/j.1600-0447.2005.00581.x.

Beck, J. S. (2011). Cognitive behavior therapy: Basics and beyond (2nd ed.). New York: Guilford Press.

Beck, A. T., \& Rector, N. A. (2005). Cognitive approaches to schizophrenia: Theory and therapy. Annual Review of Clinical Psychology, 1, 577-606.

Bellack, A. S., Muesser, K. T., Gingerich, S., \& Agresta, J. (2004). Social skills training for schizophrenia: A step-by-step guide (2nd ed.). New York, NY: Guilford Press.

Bio, D. A., \& Gattaz, W. F. (2011). Vocational rehabilitation improves cognition and negative symptoms in schizophrenia. Schizophrenia Research, 126, 265-269.

Blanchard, J. J., \& Cohen, A. S. (2006). The structure of negative symptoms within schizophrenia: Implications for assessment. Schizophrenia Bulletin, 32, 238-245.

Blanchard, J. J., Kring, A. M., Horan, W. P., \& Gur, R. (2011). Toward the next generation of negative symptom assessments: The collaboration to advance negative symptom assessment in schizophrenia. Schizophrenia Bulletin, 37, 291-299.

Bleuler, E. (1950). Dementia praecox or the group of schizophrenics. New York, NY International Universities Press Inc.

Borras, L., Boucherie, M., Mohr, S., Lecomte, T., Perroud, N., \& Huguelet, Ph. (2009) Increasing self-esteem: Efficacy of a group intervention for individuals with severe mental disorders. European Psychiatry, 24, 307-316.

Bradley, G. M., Couchman, G. M., Perlesz, A., Nguyen, A. T., Singh, B., \& Riess, C. (2006). Multiple-family group treatment for English- and Vietnamese-speaking families living with schizophrenia. Psychiatric Services, 57(4), 521-530.

Buchanan, R. W. (2007). Persistent negative symptoms in schizophrenia: An overview. Schizophrenia Bulletin, 33, 1013-1022.

Buchanan, R. W., Kreyenbuhl, J., Kelly, D. L., Noel, J. M., Boggs, D. L., Fischer, B. A., et al (2010). The 2009 schizophrenia PORT psychopharmacological treatment recommendations and summary statements. Schizophrenia Bulletin, 36, 71-93.

Buchkremer, G., Klingberg, S., Holle, R., Schulze Mönking, H., \& Hornung, W. P. (1997). Psychoeducational psychotherapy for schizophrenic patients and their key relatives or care-givers: Results of a 2-year follow-up. Acta Psychiatrica Scandinavica, 96, 483-491.

Cather, C., Penn, D., Otto, M. W., Yovel, I., Mueser, K. T., \& Goff, D. C. (2005). A pilot study of functional Cognitive Behavioral Therapy (fCBT) for schizophrenia. Schizophrenia Research, 74, 201-209. 
Cook, S., Chambers, E., \& Coleman, J. H. (2009). Occupational therapy for people with psychotic conditions in community settings: A pilot randomized controlled trial. Clinical Rehabilitation, 23, 40-52.

Crawford, M. J., Killaspy, H., Barnes, T. R. E., Batterr, B., Byford, S., Clayton, K., et al. (2012). Group art therapy as an adjunctive treatment for people with schizophrenia: Multicentre pragmatic randomised trial. BMJ, 344(e846), 1-9. http://dx.doi.org/ 10.1136/bmj.e846.

Daniels, L. (1998). A group cognitive-behavioral and process-oriented approach to treating the social impairment and negative symptoms associated with chronic mental illness. Journal of Psychotherapy Practice and Research, 7, 167-176.

Dickinson, D., Tenhula, W., Morris, S., Brown, C., Peer, J., Spencer, K., et al. (2009). A randomized, controlled trial of computerized-assisted cognitive remediation for schizophrenia. The American Journal of Psychiatry, 167, 170-180.

Dixon, L. B., Dickerson, F., Bellack, A. S., Bennett, M., Dickinson, D., Goldberg, R. W., et al. (2010). The 2009 schizophrenia PORT psychosocial treatment recommendations and summary statements. Schizophrenia Bulletin, 36, 48-70.

Dobson, D. J. G., McDougall, G., Busheikin, J., \& Aldous, J. (1995). Effects of social skills training and social milieu treatment on symptoms of schizophrenia. Psychiatric Services, 46, 376-380.

Doherty, W.J. \& McDaniel, S.H. (2010). Family therapy. Washington, D.C.: American Psychological Association. New York, NY: Oxford University Press.

Drury, V., Birchwood, M., Cochrane, R., \& Macmillan, F. (1996). Cognitive therapy and recovery from acute psychosis: A controlled trial I. Impact on psychotic symptoms. The British Journal of Psychiatry, 169, 593-601.

Dyck, D. G., Short, R. A., Hendryx, M. S., Norell, D., Myers, M., Patterson, T., et al. (2000) Management of negative symptoms among patients with schizophrenia attending multiple-family groups. Psychiatric Services, 51, 513-519.

Eack, S. M., Greenwald, D. P., Hogarty, S. S., Cooley, S. J., DiBarry, A. L., Montrose, D. M., et al. (2009). Cognitive enhancement therapy for early-course. Psychiatric Services, $60,1468-1476$.

Eack, S. M., Mesholam-Gately, R. I., Greenwald, D. P., Hogarty, S. S., \& Keshavan, M. S (in press). Negative symptom improvement during cognative rehabilitation: Results from a two-year trial of cognative enhancement threapy. Psychiatry Research. http://dx.doi.org/10.1016/j.psychres.2013.03.020 (in Press).

Erhart, S. M., Marder, S. R., \& Carpenter, W. T. (2006). Treatment of schizophrenia negative symptoms: Future prospects. Schizophrenia Bulletin, 32, 234-237.

Farreny, A., Aguado, J., Ochoa, S., Huerta-Ramos, E., Marsa, F., Lopez-Carrilero, R., et al. (2012). REPYFLEC cognitive remediation group training in schizophrenia looking for an integrative approach. Schizophrenia Research, 143, 137-144.

Favrod, J., Giuliani, F., Ernst, F., \& Bonsack, C. (2010). Anticipatory pleasure skills training A new intervention to reduce anhedonia in schizophrenia. Perspectives in Psychiatric Care, 46(3), 171-181. http://dx.doi.org/10.1111/j.1744-6163.2010.00255.x.

Gard, D. E. Kring A. M. Germans Gard, M., Horan, W. P., \& Green, M. F. (2007). Anhedonia in schizophrenia: Distinctions between anticipatory and consummatory pleasure. Schizophrenia Research, 93, 253-260.

Garety, P. A., Fowler, D. G., Freeman, D., Bebbington, P., Dunn, G., \& Kuipers, E. (2008) Cognitive-behavioural therapy and family intervention for relapse prevention and symptom reduction in psychosis: Randomised controlled trial. The British Journal of Psychiatry, 192, 412-423.

Garety, P. A., Kuipers, E., Fowler, D., Freeman, D., \& Bebbington, P. E. (2001). A cognitive model of the positive symptoms of psychosis. Psychological Medicine, 31.

Girón, M., Fernández-Yañez, A., Mañá-Alvarenga, S., Molina-Habas, A., Nolasco, A., \& Gómez-Beneyto, M. (2010). Ef ficacy and effectiveness of individual family intervention on social and clinical functioning and family burden in severe schizophrenia: A 2-year randomized controlled study. Psychological Medicine, 40(1), 73-84.

Goldstein, M. J., \& Miklowitz, D. J. (1995). The effectiveness of psychoeducational family therapy in the treatment of schizophrenic disorders. Journal of Marital and Family Therapy, 21, 361-376.

Gould, R. A., Mueser, K. T., Bolton, E., Mays, V., \& Goff, D. (2001). Cognitive therapy for psychosis in schizophrenia: An effect size analysis. Schizophrenia Research, 48 , 335-342.

Granholm, E., McQuaid, J. R., McClure, F. S., Auslander, S. A., Perivoliotis, D., Pedrelli, P., et al. (2005). A randomized, controlled trial of cognitive behavioral social skills training for middle-aged and older outpatients with chronic schizophrenia. The American Journal of Psychiatry, 162, 520-529.

Grant, P. M., \& Beck, A. T. (2009). Defeatist beliefs as a mediator of cognitive impairment, negative symptoms, and functioning in schizophrenia. Schizophrenia Bulletin, 35, 798-806.

Grant, P. M., \& Beck, A. T. (2010). Asocial beliefs as predictors of asocial behavior in schizophrenia. Psychiatry Research, 177, 65-70.

Grant, P. M., Huh, G. A., Perivoliotis, D., Stolar, N. M. \& Beck, A. T. (2012). Randomized trial to evaluate the efficacy of cognitive therapy for low-functioning patients with schizophrenia. Archives of General Psychiatry, 69, 121-127.

Gumley, A., O'Grady, M., McNay, L., Reilly, J., Power, K., \& Norrie, J. (2003). Early intervention for relapse in schizophrenia: Results of a 12-month randomized controlled trial of cognitive behavioural therapy. Psychological Medicine, 33, 419-431.

Hagen, R., Turkington, D., Berge, T., \& Grawe, R. W. (2010). CBT for psychosis: A symptombased approach. New York, NY: Routledge.

Hall, P. L., \& Tarrier, N. (2003). The cognitive-behavioural treatment of low self-esteem in psychotic patients: A pilot study. Behaviour Research and Therapy, 41, 317-332.

Hansen, J. P., Østergaard, B., Nordentoft, M., \& Hounsgaard, L. (2012). Cognitive adaptation training combined with assertive community treatment: A randomised longitudinal trial. Schizophrenia Research, 135, 105-111.

Hansen, L., Turkington, D., Kingdon, D., \& Smith (2003). Brief rating instrument for assessment of negative symptoms: Derived from the Comprehensive Psychopathological Rating Scale. International Journal of Psychiatry in Clinical Practice, 7, 113-116.
Hayes, R. L., Halford, W. K., \& Varghese, F. T. (1995). Social skills training with chronic schizophrenic patients: Effects on negative symptoms and community functioning. Behavior Therapy, 26, 433-449.

Herbener, E. S., \& Harrow, M. (2004). Are negative symptoms associated with functioning deficits in both schizophrenia and nonschizophrenia patients? A 10-year lognitudinal analysis. Schizophrenia Bulletin, 30, 813-825.

Hodge, M. A. R., Siciliano, D., Withey, P., Moss, B., Moore, G., Judd, G., et al. (2010). A randomized controlled trial of cognitive remediation in schizophrenia. Schizophrenia Bulletin, 36, 419-427.

Hogarty, G. E., Anderson, C. M., Reiss, D. J., Kornblith, S. J., Greenwald, D. P., Ulrich, R. F., et al. (1991). Family psychoeducation, social skills training, and maintenance chemotherapy in the aftercare treatment of schizophrenia: II. Two-year effects of a controlled study on relapse and adjustment. Archives of General Psychiatry, 48, 340-347.

Hogarty, G. E., Greenwald, D., Ulrich, R. F., Kornblith, S. J., DiBarry, A. L., Cooley, S., et al. (1997). Three-year trials of personal theme on adjustment of patients. The American Journal of Psychiatry, 154, 1514-1524.

Horan, W. P., Kern, R. S., Shokat-Fadai, K., Sergi, M. J., Wynn, J. K., \& Green, M. F. (2009). Social cognitive skills training in schizophrenia: An initial efficacy study of stabilized outpatients. Schizophrenia Research, 107, 47-54.

Horan, W. P., Kring, A. M., Gur, R. E., Reise, S. P., \& Blanchard, J. J. (2011). Development and psychometric validation of the Clinical Assessment Interview for Negative Symptoms (CAINS). Schizophrenia Research, 132, 140-145.

Horan, W. P., Rassovsky, Y., Kern, R. S., Lee, J., Wynn, J. K., \& Green, M. F. (2010). Further support for the role of dysfunctional attitudes in models of real-world functioning in schizophrenia. Journal of Psychiatric Research, 44, 499-505.

Jackson, H. J., McGorry, P. D., Killackey, E., Bendall, S., Allott, K., Dudgeon, P., et al. (2008). Acute-phase and 1-year follow-up results of a randomized controlled trial of CBT versus befriending for first-episode psychosis: The ACE project. Psychological Medicine, 38(5), 725-735. http://dx.doi.org/10.1017/S0033291707002061.

Jacobson, N. S., \& Truax, P. (1991). Clinical significance: A statistical approach to defining meaningful change in psychotherapy research. Journal of Consulting and Clinical Psychology, 59(1), 12-19.

Johnson, D. P., Penn, D. L., Fredrickson, B. L., Kring, A. M., Meyer, P. S., Catalino, L. I., et al. (2011). A pilot study of loving-kindness meditation for the negative symptoms of schizophrenia. Schizophrenia Research, 129, 137-140.

Jones, C., Hacker, D., Corman, I., Meaden, A., \& Irving, C. B. (2012). Cognitive behavior therapy versus other psychosocial treatments for schizophrenia. Schizophrenia Bulletin, 38, 908-910

Kay, S. R., Fiszbein, A., \& Opler, L. A. (1987). The positive and negative syndrome scale (PANSS) for schizophrenia. Schizophrenia Bulletin, 13, 261-276.

Kern, R. S., Glynn, S. M., Horan, W. P., \& Marder, S. R. (2009). Psychosocial treatments to promote functional recovery in schizophrenia. Schizophrenia Bulletin, 35, 347-361.

Kingdon, D. G., \& Turkington, D. (2005). Cognitive therapy of schizophrenia. New York, NY: The Guilford Press.

Kirkpatrick, B., Fenton, W. S., Carpenter, W. T., Jr., \& Marder, S. R. (2006). The NIMHMATRICS consensus statement on negative symptoms. Schizophrenia Bulletin, 32, 214-219.

Kirkpatrick, B., Strauss, G. P., Nguyen, L., Fischer, B. A., Daniel, D. G., Cienfuegos, A., et al. (2011). The brief negative symptom scale: Psychometric properties. Schizophrenia Bulletin, 37, 300-305.

Klingberg, S., Wittorf, A., Herrlich, J., Wiedemann, G., Meisner, C., Buchkremer, G., et al. (2009). Cognitive behavioural treatment of negative symptoms in schizophrenia patients: Study design of the TONES study, feasibility and safety of treatment. European Archives of Psychiatry and Clinical Neuroscience, 259(Suppl. 2), S149-S154.

Klingberg, S., Wolwer, W., Engel, C., Wittorf, A., Herrlich, J., Meisner, C., et al. (2011). Negative symptoms of schizophrenia as primary target of cognitive behavioral therapy: Results of the randomized clinical TONES study. Schizophrenia Bulletin, 37(Suppl. 2), S98-S110.

Kraepelin, E. (1919). Dementia praecox. Melbourne (FL): Robert E Krieger, 1913.

Krawiecka, M., Goldberg, D., \& Vaughan, M. (1977). A standardized psychiatric assessment scale for rating chronic psychotic patients. Acta Psychiatrica Scandinavica, 55, 299-308.

Kring, A. M., \& Caponigro, J. M. (2010). Emotion in schizophrenia: Where feeling meets thinking. Current Directions in Psychological Science, 19, 255-259.

Kring, A., Gur, R., Blanchard, J., Horan, W., \& Reise, S. (2013). The clinical assessment interview for negative symptoms (CAINS): Final development and validation. The American Journal of Psychiatry, 170, 165-172. http://dx.doi.org/10.1176/appi. ajp.2012.12010109.

Leclerc, C., Lesage, A. D., Ricard, N., Lecomte, T., \& Cyr, M. (2000). Assessment of a new rehabilitative coping skills module for persons with schizophrenia. The American Journal of Orthopsychiatry, 70(30), 380-388.

Lecomte, T., Leclerc, C., Corbiére, M., Wykes, T., Wallace, C. J., \& Spidel, A. (2008). Group cognitive behavior therapy or social skills training for individuals with a recent onset of psychosis? Results of a randomized controlled trial. The Journal of Nervous and Mental Disease, 196(12), 866-875.

Lecomte, T., Leclerc, C., \& Wykes, T. (2012). Group CBT for early psychosis - Are here still benefits one year later? International Journal of Group Psychotherapy, 62(2), 309-321.

Lefley, H. P. (2009). Family psychoeducation for serious mental illness. New York, NY: Oxford University Press

Leucht, S., Corves, C., Arbter, D., Engel, R. R., Li, C., \& Davis, J. M. (2009). Second-generation versus first-generation antipsychotic drugs for schizophrenia: A meta-analysis. The Lancet, 373, 31-41.

Lewis, S., Tarrier, N., Haddock, G., Bentall, R., Kinderman, P., Kingdon, D., et al. (2002). Randomised controlled trial of cognitive-behavioural therapy in early schizophrenia: Acute-phase outcomes. The British Journal of Psychiatry, 181, s91-s97. 
Lincoln, T. M., Ziegler, M., Mehl, S., Kesting, M. -L., Lullmann, E., Westermann, S., et al. (2012). Moving from efficacy to effectiveness in cognitive behavioral therapy for psychosis: A randomized clinical practice trail. Journal of Consulting and Clinical Psychology, 80(4), 674-686.

Magliano, L., Fiorillo, A., Malangone, C., De Rosa, C., Maj, M., \& The Family Intervention Working Group (2006). Patient functioning and family burden in a controlled, real-world trial of family psychoeducation for schizophrenia. Psychiatric Services, 57, 1784-1791.

McFarlane, W. R., Dushay, R. A., Stastny, P., Deakins, S. M., \& Link, B. (1996). A comparison of two levels of family-aided assertive community treatment. Psychiatric Services, 47, 744-750.

McGurk, S. R., Mueser, K. T., DeRosa, T. J., \& Wolfe, R. (2009). Work, recovery, and comorbidity in schizophrenia: A randomized control trial of cognitive remediation. Schizophrenia Bulletin, 35, 319-335.

Miklowitz, D. J., Strachan, A. M., Goldstein, M. J., Doane, J. A., Hogarty, G. E., \& Falloon, I. R. H. (1986). Expressed emotion and communication deviance in the families of schizophrenic patients. Clinician's Research Digest, 4(12).

Milev, P., Ho, B. -C., Arndt, S., \& Andreasen, N. C. (2005). Predictive values of neurocognition and negative symptoms on functional outcome in schizophrenia: A longitudinal first-episode study with 7-year follow-up. The American Journal of Psychiatry, 162, 495-506.

Morrison, A. P. (2001). The interpretation of intrusions in psychosis: An integrative cognitive approach to hallucinations and delusions. Behavioural and Cognitive Psychotherapy, 29, 257-276.

Mueser, K. T., Bond, G. R., Drake, R. E., \& Resnick, S. G. (1998). Models of community care for severe mental illness: A review of research on case management. Schizophrenia Bulletin, 24(1), 37-74.

Overall, J. E., \& Gorham, D. R. (1962). The brief psychiatric rating scale. Psychological Reports, 10, 799-812

Palma-Sevillano, C., Cañete-Crespillo, J., Farriols-Hernando, N., Cebrià-Andreu, J., Michael, M., Alonso-Fernández, I., et al. (2011). Randomised controlled trial of cognitive motivational therapy program for the initial phase of schizophrenia: A 6-month assessment. European Journal of Psychiatry, 25(2), 68-80.

Petersen, L., Jeppesen, P., Thorup, A., Abel, M. B., Øhlenschlæger, J., Christensen, T.Ø., et al. (2005). A randomised multicentre trial of integrated versus standard treatment for patients with a first episode of psychotic illness. BMJ, 1-7 (Online First).

Pilling, S., Bebbington, P., Kuipers, E., Garety, P., Geddes, J., Orbach, G., et al. (2002). Psychological treatments in schizophrenia: Meta-analysis of family intervention and cognitive behaviour therapy. Psychological Medicine, 32, 763-782.

Pinto, A., La Pia, S., Mennella, R., Giorgio, D., \& DeSimone, L. (1999). Cognitive-behavioral therapy and clozapine for clients with treatment-refractory schizophrenia. Psychiatric Services, 50, 901-904.

Rabinowitz, J., Levine, S. Z., Garibaldi, G., Bugarski-Kirola, D., Berardo, C. G., \& Kapur, S. (2012). Negative symptoms have greater impact on functioning than positive symptoms in schizophrenia: Analysis of CATIE data. Schizophrenia Research, 137, 147-150.

Rector, N. A., \& Beck, A. T. (2001). Cognitive behavioral therapy for schizophrenia: An empirical review. Journal of Nervous and Mental Disorders, 189, 278-287.

Rector, N. A., Seeman, M. V., \& Segal, Z. V. (2002). Cognitive therapy for schizophrenia: A preliminary randomized controlled trial. Schizophrenia Research, 63, 1-11.

Richardson, P., Jones, K., Evans, C., \& Rowe, A. (2007). Exploratory RCT of art therapy as an adjunctive treatment in schizophrenia. Journal of Mental Health, 16, 483-491.

Rohricht, F., \& Priebe, S. (2006). Effect of body-oriented psychological therapy on negative symptoms in schizophrenia: A randomized controlled trial. Psychological Medicine, 36, 669-678.

Rosenbaum, B., Valbak, K., Harder, S., Knudsen, P., Køster, A., Lajer, M., et al. (2006). Treatment of patients with first-episode psychosis: Two-year outcome data from the Danish national schizophrenia project. World Psychiatry, 5, 100-103.

Rosenbaum, B., Valbak, K., Harder, S., Køster, A., Lajer, M., Lindhardt, A., et al. (2005). The Danish National Schizophrenia Project: Prospective, comparative longitudinal treatment study of first-episode psychosis. The British Journal of Psychiatry, 186, 394-399.

Rus-Calafell, M., Gutierrez-Maldonado, J., Ortega-Bravo, M., Ribas-Sabate, J., \& CaqueoUrizar, A. (2013). A brief cognitive-behavioural social skills training for stabilised outpatients with schizophrenia: A preliminary study. Schizophrenia Research, 143, 327-336.

Sanz, D. G., Lorenzo, M. D., Seco, R. B., Rodríguez1, M. A., Martínez, I. L., Calleja1, R. C., et al. (2009). Efficacy of a social cognition training program for schizophrenic patients: A pilot study. The Spanish Journal of Psychology, 12(1), 184-191.
Sensky, T., Turkington, D., Kingdon, D., Scott, J. L., Scott, J., Siddle, R., et al. (2000). A randomized controlled trial of cognitive-behavioral therapy for persistent symptoms in schizophrenia resistant to medication. Archives of General Psychiatry 57, 165-172.

Startup, M., Jackson, M. C., \& Bendix, S. (2004). North Wales randomized controlled trial of cognitive behaviour therapy for acute schizophrenia spectrum disorders: Outcomes at 6 and 12 months. Psychological Medicine, 34, 413-422.

Tarrier, N., Beckett, R., Harwood, S., Baker, A., Yusupoff, L., \& Ugarteburu, I. (1993). A trial of two cognitive-behavioural methods of treating drug-resistant residual psychotic symptoms in schizophrenic patients: I. Outcome. The British Journal of Psychiatry, 162, 524-532.

Tarrier, N., Kinney, C., McCarthy, E., Wittkowski, A., Yusupoff, L., \& Gledhill, A. (2001). Are some types of psychotic symptoms more responsive to cognitive-behavorial therapy? Behavioural and Cognitive Psychotherapy, 29, 45-55.

Tarrier, N., Lewis, S., Haddock, G., Bentall, R., Drake, R., Kinderman, P., et al. (2004). Cognitive-behavioural therapy in first-episode and early schizophrenia: 18-Month follow-up of a randomised controlled trial. The British Journal of Psychiatry, 184, 231-239.

Tarrier, N., \& Wykes, T. (2004). Is there evidence that cognitive behaviour therapy is an effective treatment for schizophrenia? A cautious or cautionary tale. Behaviour Research and Therapy, 42, 1377-1401.

Thorup, A., Petersen, T. L., Jeppesen, P., Øhlenschlæger, J., Christensen, T., Krarup, G. et al. (2005). Integrated treatment ameliorates negative symptoms in first episode psychosis-Results from the Danish OPUS trial. Schizophrenia Research, 79, 95-105.

Turkington, D., Dudley, R., Warman, D. M., \& Beck, A. T. (2006). Cognitive-behavioral therapy for schizophrenia: A review. Focus, 4, 223-233.

Turkington, D., Kingdon, D., Rathod, S., Hammond, K., Pelton, J., \& Mehta, R. (2006) Outcomes of an effectiveness trial of cognitive-behavioural intervention by mental health nurses in schizophrenia. The British Journal of Psychiatry, 189, 36-40.

Turkington, D., Kingdon, D., \& Turner, T. (2002). Effectiveness of a brief cognitivebehavioural therapy intervention in the treatment of schizophrenia. The British Journal of Psychiatry, 180, 523-527.

Turkington, D., Sensky, T., Scott, J., Barnes, T. R., Nur, U., Siddle, R., et al. (2008). A randomized controlled trial of cognitive-behavior therapy for persistent symptoms in schizophrenia: A five-year follow-up. Schizophrenia Research, 98, 1-7.

Ulrich, G., Houtmans, T., \& Gold, C. (2007). The additional therapeutic effect of group music therapy for schizophrenic patients: A randomized study. Acta psychiatrica Scandinavic, 116(5), 362-370.

Valencia, M., Rascon, M. L., Juarez, F., \& Murow, E. (2007). A psychosocial skills training approach in Mexican out-patients with schizophrenia. Psychological Medicine, 37, 1393-1402.

Valmaggia, L. R., van der Gaag, M., Tarrier, N., Pijnenborg, M., \& Slooff, C. J. (2005) Cognitive-behavioural therapy for refractory psychotic symptoms of schizophrenia resistant to atypical antipsychotic medication. Randomised controlled trial. The British Journal of Psychiatry, 186, 324-330.

Villalta-Gil, V., Roca, M., Gonzalez, N., Domenec, E., Cuca, E. A., Asensio, M. R., et al. (2009). Dog-assisted therapy in the treatment of chronic schizophrenia inpatients. Anthrozoös, 22(2), 149-159.

WHO (1988). WHO psychiatric disability assessment schedule (WHO-DAS). Geneva: World Health Organization.

Wing, J. K. (1961). A simple and reliable subclassification of chronic schizophrenia. Journal of Mental Science, 107, 862-875.

Wykes, T., Reeder, C., Landau, S., Everitt, B., Knapp, M., Patel, A., et al. (2007). Cognitive remediation therapy in schizophrenia. The British Journal of Psychiatry, 190, 421-427.

Wykes, T., Steel, C., Everitt, B., \& Tarrier, N. (2008). Cognitive behavior therapy for schizophrenia: Effect sizes, clinical models, and methodological rigor. Schizophrenia Bulletin, 34, 523-537.

Wynne, L. C. (Ed.). (1988). The State of the art in family therapy research: Controversies and recommendations. New York, NY: Guilford Press.

Xiang, Y., Weng, Y., Li, W., Gao, L., Chen, G., Xie, L., et al. (2006). Training patients with schizophrenia with the community re-entry model. Social Psychiatry and Psychiatric Epidemiology, 41, 464-469.

Yildiz, M., Veznedaroglu, B., Eryavuz, A., \& Kayahan, B. (2004). Psychosocial skills training on social functioning and quality of life. International Journal of Psychiatry in Clinical Practice, 8, 219-225.

Zimmermann, G., Favrod, J., Trieu, V. H., \& Pomini, V. (2005). The effect of cognitive behavioral treatment on the positive symptoms of schizophrenia spectrum disorders: A meta-analysis. Schizophrenia Research, 77, 1-9.

Zubin, J., \& Spring, B. (1977). Vulnerability-A new view of schizophrenia. Journal of Abnormal Psychology, 86, 103-126. 